OPEN ACCESS

Edited by:

Kazimierz Trebacz,

Maria Curie-Skłodowska University,

Poland

Reviewed by:

Vladimir Vodeneev,

N. I. Lobachevsky State University of Nizhny Novgorod, Russia

Rafael Ribeiro,

Universidade Estadual de Campinas,

Brazil

*Correspondence:

Weibiao Liao

liaowb@gsau.edu.cn

tThese authors have contributed equally to this work.

Specialty section:

This article was submitted to

Plant Physiology,

a section of the journal

Frontiers in Plant Science

Received: 13 June 2017 Accepted: 13 September 2017 Published: 27 September 2017

Citation:

Niu L, YU J, Liao W, Yu J, Zhang M and Dawuda MM (2017) Calcium and Calmodulin Are Involved in Nitric Oxide-Induced Adventitious Rooting of Cucumber under Simulated Osmotic Stress.

Front. Plant Sci. 8:1684. doi: 10.3389/fpls.2017.01684

\section{Calcium and Calmodulin Are Involved in Nitric Oxide-Induced Adventitious Rooting of Cucumber under Simulated Osmotic Stress}

\author{
Lijuan Niu't, Jian Yu' ${ }^{1 t}$, Weibiao Liao ${ }^{1 *}$, Jihua Yu ${ }^{1}$, Meiling Zhang ${ }^{2}$ and \\ Mohammed M. Dawuda ${ }^{1,3}$ \\ ${ }^{1}$ College of Horticulture, Gansu Agricultural University, Lanzhou, China, ${ }^{2}$ College of Science, Gansu Agricultural University, \\ Lanzhou, China, ${ }^{3}$ Department of Horticulture, Faculty of Agriculture, University for Development Studies, Tamale, Ghana
}

Osmotic stress is a major form of abiotic stress that adversely affects growth and development of plants and subsequently reduces yield and quality of crops. In this study, the effect of nitric oxide (NO) and calcium $\left(\mathrm{Ca}^{2+}\right)$ on the process of adventitious rooting in cucumber (Cucumis sativus L.) under simulated osmotic stress was investigated. The results revealed that the effect of exogenous $\mathrm{NO}$ and $\mathrm{Ca}^{2+}$ in promoting the development of adventitious roots in cucumber seedlings under simulated osmotic stress was dose-dependent, with a maximal biological response at $10 \mu \mathrm{M} N O$ donor nitroprusside (SNP) or $200 \mu \mathrm{M} \mathrm{Ca}{ }^{2+}$. The application of $\mathrm{Ca}^{2+}$ chelators or channel inhibitors and calmodulin (CaM) antagonists significantly reversed NOinduced adventitious rooting, implying that endogenous $\mathrm{Ca}^{2+} / \mathrm{CaM}$ might be involved in NO-induced adventitious rooting under osmotic stress. Moreover, intracellular $\mathrm{Ca}$ amount was also increased by $\mathrm{NO}$ in cucumber hypocotyls during the development of adventitious roots under osmotic stress. This increase of endogenous $\mathrm{Ca}^{2+}$ was inhibited by NO specific scavenger 2-(4-carboxyphenyl) -4,4,5,5-tetramethylimidazoline1-oxyl-3-oxide potassium salt (CPTIO), nitrate reductase inhibitors tungstate $\left(\mathrm{Na}_{2} \mathrm{WO}_{4}\right)$ and sodium azide $\left(\mathrm{NaN}_{3}\right)$. This gives an indication that $\mathrm{Ca}^{2+}$ might be a downstream signaling molecule in the adventitious root development by $\mathrm{NO}$ under osmotic condition. The results also show that $\mathrm{NO}$ or $\mathrm{Ca}^{2+}$ play a positive role in improving plant water status and photosynthetic system by increasing chlorophyll content and photochemical activity in leaves. Furthermore, $\mathrm{NO}$ and $\mathrm{Ca}^{2+}$ treatment might alleviate the negative effects of osmotic stress by decreasing membrane damage and reactive oxygen species (ROS) production by enhancing the activities of superoxide dismutase (SOD), catalase (CAT) and ascorbate peroxidase (APX). Therefore, $\mathrm{Ca}^{2+} / \mathrm{CaM}$ may act as a downstream signaling molecule in NO-induced development of adventitious root under simulated osmotic stress through improving the photosynthetic performance of leaves and activating antioxidative system in plants.

Keywords: abiotic stress, adventitious rooting, nitric oxide, calcium, chlorophyll fluorescence, antioxidant system 


\section{INTRODUCTION}

Nitric oxide (NO), as a free radical gas, has been synthesized enzymatically or non-enzymatically (Skiba et al., 1993; Rockel et al., 2002). Previous reports have indicated that NO might regulate the growth and physiological processes in plants, including seed germination (Beligni and Lamattina, 2000; Wang et al., 2015), root growth and development (Liao et al., 2011; Zhao et al., 2015), senescence (Liao et al., 2013), stomatal closure (Neill et al., 2002; Shi C. et al., 2015) and the growth of pollen tube (Wang et al., 2009). It has also been reported that NO plays an essential role in response to various abiotic stresses (Garcia-Mata and Lamattina, 2001; Salgado et al., 2013; Kaur et al., 2015; Liu W. et al., 2015). Besides, an increasing body of evidence indicated that NO served as a regulator in plant response to osmotic stress. Liao et al. (2012a) found that exogenous NO improved the development of adventitious roots in marigold explants under drought stress conditions by improving photosynthesis and carbohydrate and nitrogen contents. Shan et al. (2015) have reported that jasmonic acid (JA) alleviated drought stress by inducing endogenous NO, which could up-regulate the activity of ASA-GSH cycle. In addition, Jday et al. (2016) found that exogenous application of NO increased drought tolerance and mitigated damage by regulating proline metabolism and reducing oxidative damage by increasing the activities of superoxide dismutase (SOD) and catalase (CAT) in Cakile maritima.

Increasing evidence pointed out that the change of intracellular $\mathrm{Ca}^{2+}$ concentration is a mark of signaling transduction to mediate various cellular processes in plants (Kong et al., 2015; Tang et al., 2015). Recently, it has been reported that $\mathrm{Ca}^{2+}$ regulates the processes of growth and development in plants including seed germination (Kong et al., 2015), pollen tube growth (Zhou et al., 2014), and root growth (Liao et al., 2012b). Some studies have indicated that variations in cytosolic free $\mathrm{Ca}^{2+}$ concentration might be involved in plant response to different kinds of abiotic stresses (Zou et al., 2015; Li et al., 2016). $\mathrm{Ca}^{2+}$ plays a role in mediating plant adaptation to drought stress condition. For instance, Zou et al. (2010) found that $\mathrm{Ca}^{2+}$ could mediate stomatal movements in Arabidopsis plants under drought stress through calcium-dependent protein kinases (CDPKs). Application of $\mathrm{Ca}^{2+}$ also reduced drought-induced proline accumulation, which implied that $\mathrm{Ca}^{2+}$ played a role in response to drought stress in Triticum aestivum L. (Sadiqov et al., 2002). However, the mechanism of $\mathrm{Ca}^{2+}$ signaling in regulating plant growth and response to abiotic stress still needs further investigation.

The interaction of $\mathrm{NO}$ and $\mathrm{Ca}^{2+}$ has been regarded as a critical regulator in plant growth and development and in response to abiotic stress. For example, Lanteri et al. (2006) reported that $\mathrm{Ca}^{2+}$ is involved in NO-induced adventitious root formation in cucumber. Chen and Kao (2012) found that $\mathrm{Ca}^{2+}$ was involved in NO-induced formation of lateral roots (LR) in rice. Excluding endogenous $\mathrm{Ca}^{2+}$ inhibited the NOinduced LR formation. However, the authors did not find any relationship between $\mathrm{Ca}^{2+}$ and endogenous NO during LR formation. A crosstalk between $\mathrm{NO}$ and $\mathrm{Ca}^{2+}$ in inducing adventitious rooting in marigold under normal condition has been reported (Liao et al., 2012b). In addition, $\mathrm{Ca}^{2+}$ signaling induced endogenous $\mathrm{NO}$ accumulation by inducing hydrogen peroxide $\left(\mathrm{H}_{2} \mathrm{O}_{2}\right)$ generation during stomatal closure in Arabidopsis guard cells (Wang et al., 2012). Xu et al. (2016) also found an interaction between $\mathrm{NO}$ and $\mathrm{Ca}^{2+}$ under high irradiance in tall fescue leaves. The occurrence of a crosstalk between $\mathrm{NO}$ and $\mathrm{Ca}^{2+}$ under copper stress was also found in Ulva compressa (González et al., 2012). NO generation under copper stress might be dependent on $\mathrm{Ca}^{2+}$ release through various $\mathrm{Ca}^{2+}$ channels, which were also activated by $\mathrm{NO}$ (González et al., 2012). Cellular responses to $\mathrm{NO}$ and $\mathrm{Ca}^{2+}$ signaling are complicated, therefore, further research to deepen our understanding of the crosstalk between $\mathrm{NO}$ and $\mathrm{Ca}^{2+}$ in plants is needed.

Osmotic stress as a situation which might prevent plants from absorbing enough water induces the inhibition of plant growth and oxidative damage (Jiang et al., 1993). The common osmotic stresses include drought, salt and cold stresses. It has been reported that osmotic stress significantly reduced the fresh weight and water content in leaf blade and leaf petiole of sugar beet (Beta vulgaris L.) (Wu et al., 2016). Osmotic stress interfered with various metabolic processes (Búfalo et al., 2016) in plants such as photosynthesis (Bündig et al., 2016) and respiration (Zorrilla-Fontanesi et al., 2016). Previous study has shown that $\mathrm{Ca}^{2+}$ and CDPK could be involved in adventitious rooting, which was induced by NO in cucumber (Lanteri et al., 2006). However, Liao et al. (2012b) indicated that NO induced adventitious root development in marigold through enhancing endogenous $\mathrm{Ca}^{2+}$ and $\mathrm{CaM}$ level under stress-free conditions. The role of $\mathrm{NO}$ and $\mathrm{Ca}^{2+}$ in adventitious rooting under abiotic stress is unknown. We conduct this experiment with the hypothesis that $\mathrm{NO}, \mathrm{Ca}^{2+}$ and their crosstalk may affect adventitious development in plants under abiotic stress. The objective of this study was to elucidate the potential role of $\mathrm{NO}$ and $\mathrm{Ca}^{2+}$ in adventitious rooting process under osmotic stress condition. In this study, we provide evidence that $\mathrm{Ca}^{2+} / \mathrm{CaM}$ are required for NO-induced adventitious root development in cucumber under osmotic stress and this improves our understanding of the mechanism of NO signaling transduction under abiotic stress.

\section{MATERIALS AND METHODS}

\section{Plant Materials}

Cucumber (Cucumis sativus 'Xinchun 4') seeds were germinated in petri dishes on filter papers moistened with distilled water and maintained at $25 \pm 1 \mathrm{C}$ for 6 days with a $14 \mathrm{~h}$ photoperiod (photosynthetically active radiation $=200 \mu \mathrm{mol} \mathrm{s}^{-1} \mathrm{~m}^{-2}$ ). Primary roots of 6 days old seedlings were removed and the cucumber explants were then maintained under the same conditions of temperature and photoperiod for another 6 days in the presence of different media as indicated below. These media were changed every day in order to keep the solution fresh. Root number and length per explant were counted and measured. 


\section{Treatments of Explants}

Experiment 1: Polyethylene glycol 6000 (PEG 6000, Shanghai Chemical Reagent Co. Ltd., Shanghai, China) was used to simulate osmotic stress. Explants were placed in Petri dishes containing filter paper moistened with distilled water (control) and different concentrations of PEG 6000, sodium nitroprusside (SNP, a donor of NO, Merck, Darmstadt, Germany) and calcium chloride $\left(\mathrm{CaCl}_{2}\right.$, Solarbio, Beijing, China) and kept at $25 \pm 1{ }^{\circ} \mathrm{C}$. The following chemicals were added with suitable concentration of PEG, SNP, or $\mathrm{CaCl}_{2}: 50 \mu \mathrm{M}$ S-nitroso- $N$ acetylpenicillamine (SNAP, a donor of NO, Sigma, United States), $50 \mu \mathrm{M} \mathrm{K}_{4} \mathrm{Fe}(\mathrm{CN})_{6}$ (SNP analog, Solarbio, Beijing, China), $100 \mu \mathrm{M}$ sodium nitrate $\left(\mathrm{NaNO}_{3}\right.$, degradation product of SNP, Solarbio, Beijing, China).

Experiment 2: Ca chelators and channel inhibitors and CaM antagonists: (1) $100 \mu \mathrm{M}$ ethylene glycol-bis (2-aminoethylether)$N, N, N^{\prime}, N^{\prime}$-tetraacetic acid (EGTA, Sigma, United States ): a $\mathrm{Ca}^{2+}$ chelator (Liao et al., 2012b); (2) $30 \mu \mathrm{M}$ 1,2-bis (o-aminophenoxy) ethane- $N, N, N^{\prime}, N^{\prime}$-tetraacetic acid tetra (acetoxymethyl) ester (BAPTA/AM, Santa Cruz, CA, United States; BAPTA-AM was prepared for $15 \mathrm{~min}$ at $-20^{\circ} \mathrm{C}$ before the experiment): a membrane permeable $\mathrm{Ca}^{2+}$ chelator (Liao et al., 2012b); (3) $80 \mu \mathrm{M} \mathrm{N}$-(6-aminohexyl)-5-chloro-1-naphthalenesulfonamide hydrochloride (W-7, Santa Cruz, CA, United States): a CaM antagonist (González et al., 2012); (4) $80 \mu \mathrm{M} \mathrm{N}$-(6-aminohexyl)1-naphthalenesulfonamide (W-5, Santa Cruz, CA, United States): a CaM antagonist (Liao et al., 2012b); (5) $100 \mu \mathrm{M}$ trifluoperazine dihydrochloride (TFP, Santa Cruz, CA, United States): a CaM antagonist (Lanteri et al., 2006); (6) $500 \mu \mathrm{M}$ lanthanum chloride $\left(\mathrm{LaCl}_{3}\right.$, Solarbio, Beijing, China): a $\mathrm{Ca}^{2+}$ channel blocker (Lanteri et al., 2006); (7) $150 \mu \mathrm{M}$ nifedipine (Solarbio, Beijing, China): a $\mathrm{Ca}^{2+}$ channel blocker (Reiss and Herth, 1985).

Experiment 3: NO scavengers and nitrate reductase inhibitors: (1) $200 \mu \mathrm{M}$ 2-(4-carboxy-2-phenyl)-4, 4, 5, 5tetramethylimidazoline-1-oxyl-3-oxide (cPTIO, Sigma, United States): a NO specific scavenger (Liao et al., 2012b); (2) $10 \mu \mathrm{M}$ sodium azide $\left(\mathrm{NaN}_{3}\right.$, Solarbio, Beijing, China): a nitrate reductase inhibitor (Liao et al., 2013); (3) $100 \mu \mathrm{M}$ sodium tungstate $\left(\mathrm{Na}_{2} \mathrm{WO}_{4}\right.$, Solarbio, Beijing, China): a nitrate reductase inhibitor (Tian et al., 2007). The concentrations of these chemicals were based on the results of a preliminary experiment.

\section{Cytosolic Free $\mathrm{Ca}^{2+}$ Observation}

Fluo-3/AM (Sigma, United States) as molecular probes was utilized to determine intracellular Ca level in plant. $20 \mu \mathrm{M}$ Fluo3/AM was loaded into cucumber hypocotyls (about $100-200 \mathrm{~mm}$ long) at $4^{\circ} \mathrm{C}$ in the dark (Zhang et al., 1998). After $2 \mathrm{~h}$ of incubation, the hypocotyls were washed three times with distilled water to remove the excess of fluorescence and place under $20^{\circ} \mathrm{C}$ for $1 \mathrm{~h}$. The Fluo-3 fluorescence of the hypocotyls after $48 \mathrm{~h}$ of treatments was visualized via fluorescence microscope (Leica $400 \times$, Planapo, Wetzlar, Germany), for an excitation wavelength of $488 \mathrm{~nm}$ and an emission wavelength of 520-530 nm. After that, the fluorescence intensity of endogenous $\mathrm{Ca}^{2+}$ at $48 \mathrm{~h}$ was measured via Image Pro software (Media Cyberntics, United States).

\section{Determination of Endogenous NO Production}

Fluorescent probe 4-amino-5-methylamino- $2^{\prime}, 7^{\prime}$-diaminofluoresceindiacetate (DAF-FM DA) was utilized to measure the level of endogenous NO in cucumber hypocotyls after $48 \mathrm{~h}$ of treatments. The hypocotyls were loaded with $10 \mu \mathrm{M}$ DAF-FM DA (Graziano and Lamattina, 2007) in $50 \mathrm{mM}$ Tris- $\mathrm{HCl}(\mathrm{pH}$ 7.4) for $2 \mathrm{~h}$ in the dark. Then, the samples were washed three times with fresh buffer for $15 \mathrm{~min}$. DAF-FM DA fluorescence was visualized via fluorescence microscope (Leica $400 \times$, Planapo, Wetzlar, Germany), for excitation with the $488 \mathrm{~nm}$, and emission with $500-530 \mathrm{~nm}$.

\section{Measurement of Water Potential}

The water potential of cucumber leaves was directly determined using a dew-point water potential meter WP4T (Decagon Devices, United States). The measurements of water potential in cucumber leaves after $48 \mathrm{~h}$ of treatment were made at 9:00 - 10:00 am.

\section{Determination of TBARS, $\mathrm{H}_{2} \mathrm{O}_{2}$ and $\mathrm{O}_{2}{ }^{-}$ Content}

TBARS content was determined as described by Cakmak and Horst (1991). $0.2 \mathrm{~g}$ fresh explant was grounded with $3 \mathrm{~mL}$ of $0.1 \%(\mathrm{w} / \mathrm{v})$ trichloroacetic acid (TCA). The homogenate was centrifuged at $12000 \mathrm{~g}$ for $5 \mathrm{~min}, 1 \mathrm{~mL}$ supernatant was added to $4 \mathrm{~mL}$ of $20 \%(\mathrm{w} / \mathrm{v})$ TCA which included $0.5 \%(\mathrm{w} / \mathrm{v})$ TBA. Then, samples were incubated in a water-bath $(30 \mathrm{~min})$ at $90^{\circ} \mathrm{C}$. After that, the reaction was incubated in ice bath. After $10000 \mathrm{~g}$ centrifugation for $5 \mathrm{~min}$, the absorbance of the supernatant was recorded at 532 and $600 \mathrm{~nm}$.

$\mathrm{H}_{2} \mathrm{O}_{2}$ content was determined the method of Velikova et al. (2000). $0.2 \mathrm{~g}$ sample was homogenized with $4 \mathrm{~mL}$ of $0.1 \%(\mathrm{w} / \mathrm{v})$ trichloacetic acid in an ice bath. After $12000 \mathrm{~g}$ centrifugation at $4^{\circ} \mathrm{C}$ for $15 \mathrm{~min}$, the absorbance of the mixture reaction which includes $0.5 \mathrm{~mL}$ of the supernatant, $0.5 \mathrm{~mL}$ of $10 \mathrm{mM}$ potassium phosphate buffer $(\mathrm{pH} 7.0)$ and $1 \mathrm{~mL}$ of $1 \mathrm{M}$ potassium iodide was recorded at $390 \mathrm{~nm}$.

The rate of superoxide production $\left(\mathrm{O}_{2}^{-}\right)$was measured according to Chaitanya and Naithani (1994). Fresh cucumber explant $(0.2 \mathrm{~g})$ was homogenized with $100 \mathrm{mM}$ sodiumphosphate buffer $(\mathrm{pH}$ 7.8) in an ice bath. The centrifugation was performed for $20 \mathrm{~min}$ at $4^{\circ} \mathrm{C}$. The mixture includes $0.5 \mathrm{~mL}$ of $100 \mathrm{mM}$ sodium phosphate buffer $(\mathrm{pH} 7.8)$, $0.5 \mathrm{~mL}$ of $1 \mathrm{mM}$ hydroxylammonium chloride and $0.5 \mathrm{~mL}$ of supernatant. Then, $1 \mathrm{~mL}$ of $17 \mathrm{mM}$ sulfanilic acid and $1 \mathrm{~mL}$ of $7 \mathrm{mM} \alpha$-naphthylamine were added in the reaction which was maintained at $25^{\circ} \mathrm{C}$ for $20 \mathrm{~min}$. The absorbance of sample was measured at $540 \mathrm{~nm}$. ROS production was measured after $48 \mathrm{~h}$ of treatments.

\section{Determination of Chlorophyll Content}

About $0.2 \mathrm{~g}$ leaves were ground to a fine powder and extracted with $5 \mathrm{~mL}$ of $80 \%$ acetone $(\mathrm{v} / \mathrm{v})$. The amounts of Chlorophyll $\mathrm{a}, \mathrm{b}$, or $\mathrm{a}+\mathrm{b}$ after $48 \mathrm{~h}$ of treatments were determined by spectrophotometer, measuring the absorbance at 645 and $663 \mathrm{~nm}$ 
and the chlorophyll concentration (mg/g DW) was calculated by using the equations according to Arnon (1949).

\section{Measurement of Chlorophyll Fluorescence}

This was measured as described by Genty et al. (1989). Fluorescence parameters of cucumber leaves after $48 \mathrm{~h}$ were measured using chlorophyll fluorescence imaging system (MAXI Imaging-PAM, Walz, Effeltrich, Germany) at $25^{\circ} \mathrm{C}$. The intensities of the modulated measuring beam, actinic light and saturating light were $0.1 \mu \mathrm{mol} \mathrm{m} \mathrm{m}^{-2} \mathrm{~s}^{-1}, 81 \mu \mathrm{mol}$ $\mathrm{m}^{-2} \mathrm{~s}^{-1}$ and $2700 \mu \mathrm{mol} \mathrm{m} \mathrm{m}^{-2} \mathrm{~s}^{-1} \mathrm{PFD}$, respectively. The duration of saturation pulses was $0.8 \mathrm{~s}$. Meanwhile, the duration of actinic light was set to $5 \mathrm{~min}$ to obtain chlorophyll fluorescence under the steady state condition. After putting the plant samples to $30 \mathrm{~min}$ dark period adaptation, the initial fluorescence yield $\left(F_{\mathrm{O}}\right)$ was obtained. The maximum fluorescence yield $(F m)$ was measured with the application of a saturation pulse. Variable chlorophyll fluorescence $(F v)$ was evaluated as $F v=F m-F o$. The maximum quantum yield of PSII $(F v / F m)$ were calculated as $F v / F m=(F m-F o) / F m$. Maximum fluorescence yield of the light adapted leaf ( $F m^{\prime}$ ) were obtained after the application of a saturation pulse and Fs represented steady-state chlorophyll fluorescence. Effective quantum yield of PSII $(\Phi$ PSII $)=\left(F m^{\prime}-F s\right) / F m^{\prime}$. After turning off action light, far red light $\left(10 \mu \mathrm{mol} \mathrm{m} \mathrm{m}^{-2} \mathrm{~s}^{-1}\right)$ was illuminated immediately obtaining the minimum fluorescence yield in light-adapted state $\left(F O^{\prime}\right)$. Photochemical quenching $\left(\mathrm{qP}=\left[F^{\prime} m^{-}\right.\right.$ $\left.F s] /\left[F^{\prime}-F o^{\prime}\right]\right)$ and non-photochemical (NPQ $=[F m-$ $\left.\left.\mathrm{Fm}^{\prime}\right] / \mathrm{Fm}^{\prime}\right]$ ) quenching coefficients were calculated (Liu Z. et al., 2015).

\section{Antioxidant Enzyme Assays}

Frozen explant (approximately $200 \mathrm{mg}$ ) were homogenized in $5 \mathrm{~mL}$ of $50 \mathrm{mM}$ sodium phosphate buffer ( $\mathrm{pH} 7.8$ ) containing $5 \mathrm{mM}$ ethylenediaminetetraacetic acid and $2 \%$ polyvinylpyrrolidone for SOD and CAT assay or the combination with the addition of $2 \mathrm{mM}$ ascorbic acid (ASC) for ascorbate peroxidase (APX) assay. The homogenate was centrifuged at $12000 \mathrm{~g}$ for $20 \mathrm{~min}$ at $4^{\circ} \mathrm{C}$ and the supernatant was used as the crude enzyme extract. Total SOD activity was measured according to Dhindsa et al. (1981). The definition of one unit of SOD was the amount of crude enzyme extract required to inhibit the reduction rate of Nitrotetrazolium Blue chloride (NBT) by 50\%. APX activity was evaluated by measuring the decrease in absorbance at $290 \mathrm{~nm}$ of a reaction mixture including $25 \mathrm{mM}$ sodium phosphate buffer containing $0.1 \mathrm{mM}$ ethylenediaminetetraacetic acid ( $\mathrm{pH} 7.0$ ), $20 \mathrm{mM} \mathrm{H}_{2} \mathrm{O}_{2}, 5 \mathrm{mM}$ ASC and $0.1 \mathrm{~mL}$ enzyme extract as previously described by Nakano and Asada (1981). According to Aebi (1984), CAT activity was evaluated by monitoring the consumption of $\mathrm{H}_{2} \mathrm{O}_{2}$ at $240 \mathrm{~nm}$ by a reaction mixture including $25 \mathrm{mM}$ sodium phosphate buffer, $0.1 \mathrm{mM}$ ethylenediaminetetraacetic acid ( $\mathrm{pH} 7.0$ ), $100 \mathrm{mM} \mathrm{H}_{2} \mathrm{O}_{2}$ and $0.1 \mathrm{~mL}$ enzyme extract. The activities of antioxidant enzymes were measured after $48 \mathrm{~h}$ of treatments.

\section{Statistical Analysis of the Data}

All the results in the figures and table were expressed as the mean values \pm SE from three independent replicates (10 samples per replication). Data was analyzed using the Statistical Package for Social Sciences for Windows (version 13.00; SPSS, Inc., Chicago, IC, United States). Analysis of Variance (ANOVA) was done and statistical differences among treatments were analyzed through Duncan's multiple range test $(P<0.05)$.

\section{RESULTS}

\section{Effect of Exogenous SNP and $\mathrm{CaCl}_{2}$ on Adventitious Rooting under Osmotic Stress}

To assess the effect of PEG on adventitious rooting in cucumber, we performed a dose-response experiment with PEG. When different concentrations of PEG solution were applied, the amount of adventitious roots and root length decreased significantly (Figure 1). As shown in Figure 1, root number and root length under $0.05 \%$ PEG decreased to about half that of the control treatment. Therefore, $0.05 \%$ PEG was utilized to simulate osmotic stress in the following experiments.

In order to investigate the effects of $\mathrm{NO}$ on the development of adventitious root under osmotic stress, cucumber explants were treated with different concentrations of SNP (a donor of NO). As shown in Figure 2, lower concentrations of SNP (1, 10 , and $50 \mu \mathrm{M})$ treatments significantly increased the number
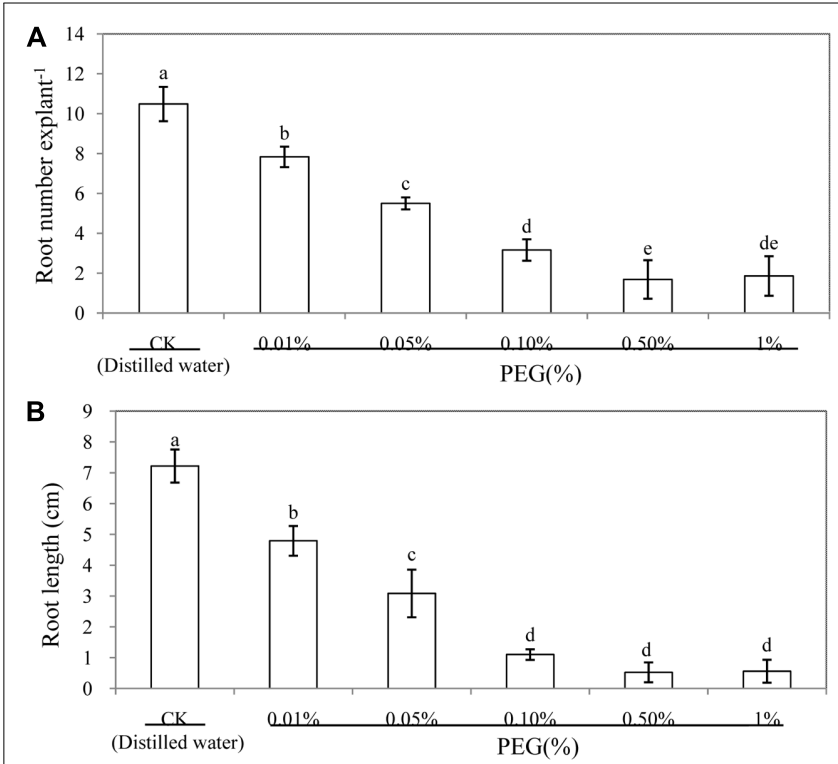

FIGURE 1 | Effect of different concentrations of PEG on adventitious root development in cucumber explants. The primary roots were removed from hypocotyl of 6 -day-old seedlings. Explants were incubated for 6 days with different concentrations of PEG 6000. The numbers (A) and root length (B) of adventitious root were expressed as mean \pm SE $(n=3,10$ explants were used per replicate). Bars with different lower case letters were significantly different by Duncan's multiple range test $(p<0.05)$. 

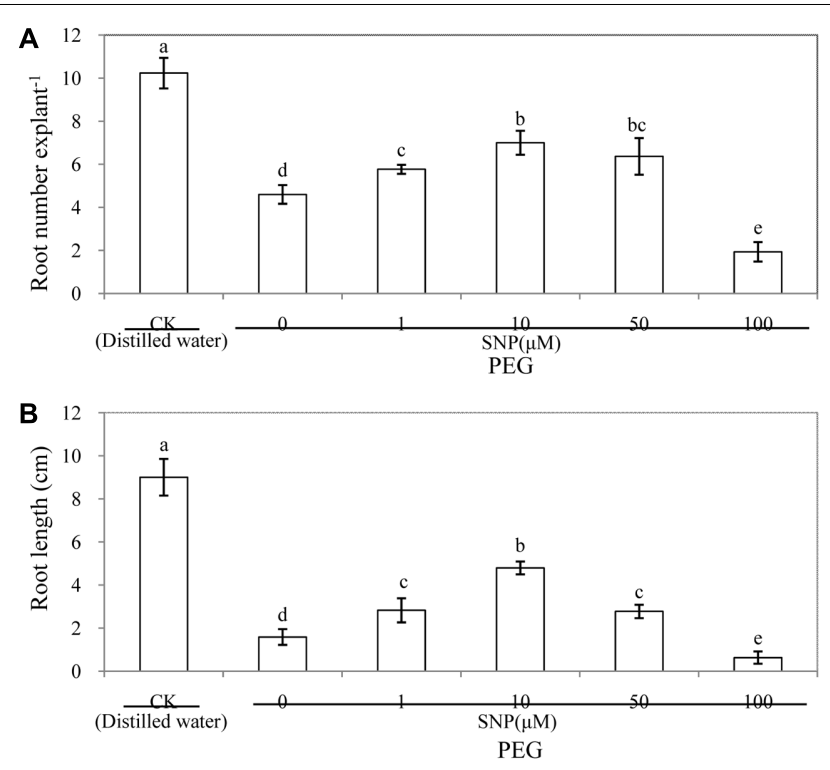

FIGURE 2 | Effect of different concentrations of SNP on adventitious root development in cucumber explants under osmotic stress. The primary roots were removed from hypocotyl of 6-day-old seedlings. Explants were incubated for 6 days with distilled water (control) or 0.05\% (w/v) PEG 6000 plus different concentrations of SNP. The numbers of adventitious root (A) and root length (B) were expressed as mean \pm SE $(n=3,10$ explants were used per replicate). Bars with different lower case letters were significantly different by Duncan's multiple range test $(p<0.05)$.
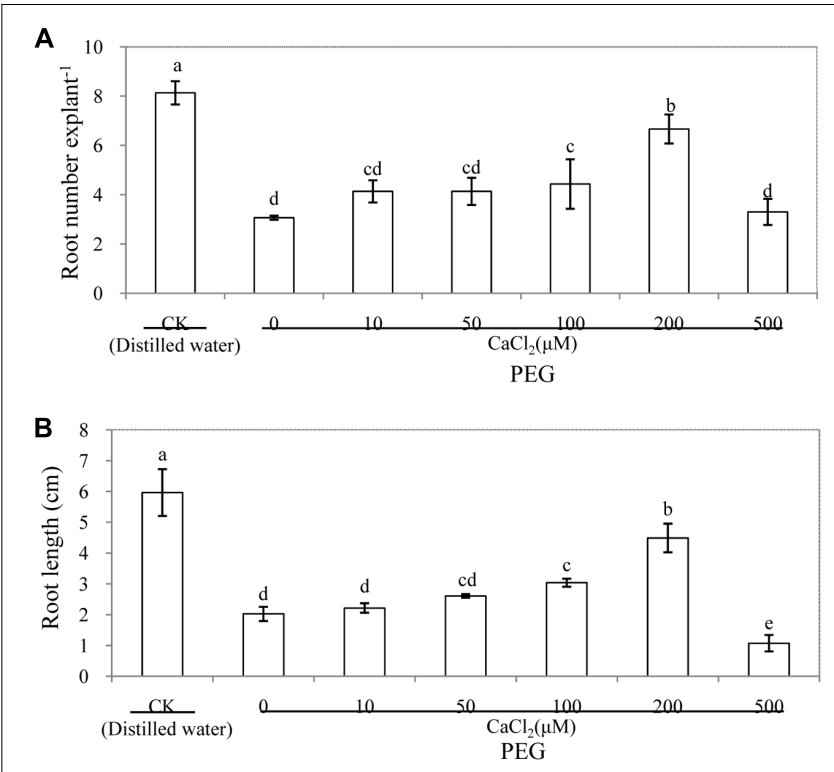

FIGURE 3 | Effects of different concentrations of $\mathrm{CaCl}_{2}$ on adventitious root development in cucumber explants under osmotic stress. The primary roots were removed of 6 -day-old seedlings. Explants were incubated for 6 days with distilled water (control) or $0.05 \%$ (w/v) PEG 6000 plus different concentrations of $\mathrm{CaCl}_{2}$. Adventitious root numbers $(\mathbf{A})$ and root length (B) were expressed as mean \pm SE ( $n=3,10$ explants was used per replicate). Bars with different lower case letters were significantly different by Duncan's multiple range test $(p<0.05)$. of adventitious roots and root length under osmotic stress. However, a higher dose (100 $\mu$ M SNP) significantly decreased the root number and root length, which indicates that the effect of NO on root number of adventitious roots was dosedependent under osmotic stress, with a maximal biological response at $10 \mu \mathrm{M}$ SNP (Figure 2 and Supplementary Figure S1). Additionally, root numbers and root length of $10 \mu \mathrm{M}$ SNP treatment increased by 52.2 and $201.9 \%$, respectively, compared with those of PEG treatment. These results indicate that $10 \mu \mathrm{M}$ SNP might significantly reverse the adverse effect of osmotic stress and promote the development of adventitious roots. Thus, $10 \mu \mathrm{M}$ SNP was utilized for further experiments to study the processes of adventitious rooting under osmotic stress.

As shown in Figure 3, the number and length of adventitious roots were significantly affected by different concentrations of $\mathrm{CaCl}_{2}$ treatments under osmotic stress. Exogenous $\mathrm{CaCl}_{2}$ treatments showed a concentration-dependent effect on adventitious rooting. There was no marked difference between 0,10 , and $50 \mu \mathrm{M} \mathrm{CaCl}_{2}$. Meanwhile, root number from 100 and $200 \mu \mathrm{M} \mathrm{CaCl}$-treated explants increased by 44.3 and $117.3 \%$, respectively, compared with those of the PEG treatment. In addition, application of $200 \mu \mathrm{M} \mathrm{CaCl}_{2}$ significantly increased the root length by $121.2 \%$ in comparison with the PEG treatment alone. The number and length of adventitious roots decreased greatly at $\mathrm{CaCl}_{2}$ concentration of $500 \mu \mathrm{M}$ (Figure 3 and Supplementary Figure S2). Among the different concentrations of $\mathrm{CaCl}_{2}$ treatments, $200 \mu \mathrm{M} \mathrm{CaCl} 2$ significantly increased the root number and root length and had the greatest effect in promoting the development of adventitious root under osmotic stress. Therefore, we utilized $200 \mu \mathrm{M} \mathrm{CaCl}_{2}$ in the following experiments.

\section{Effect of $\mathrm{Ca}^{2+}$ Chelators, Channel Inhibitors and CaM Antagonists on Adventitious Rooting under Osmotic Stress}

In order to further investigate the requirement of $\mathrm{Ca}^{2+} / \mathrm{CaM}$ for NO-induced adventitious rooting, $\mathrm{Ca}^{2+}$ chelators (EGTA, BAPTA/AM), $\mathrm{Ca}^{2+}$ channel inhibitors $\left(\mathrm{LaCl}_{3}\right.$ or nifedipine) and CaM antagonist (TFP, W-7 and W-5) were applied in this study (Figure 4). The results showed that EGTA, BAPTA/AM, $\mathrm{LaCl}_{3}$ and nifedipine significantly inhibited the development of adventitious roots under osmotic stress. Similarly, TFP and W7 treatments also had a significant reduction in adventitious rooting. However, W-5, acting as a CaM antagonist, hardly reduced adventitious root number and length. SNP, $\mathrm{CaCl}_{2}$ and $\mathrm{SNP}+\mathrm{CaCl}_{2}$ treatments obviously alleviated osmotic stress and promoted the development of adventitious roots (Figure 4 and Supplementary Figure S3).

\section{Effect of $\mathrm{K}_{4} \mathrm{Fe}(\mathrm{CN})_{6}$, SNAP and cPTIO on Adventitious Rooting under Osmotic Stress}

Here, $\mathrm{K}_{4} \mathrm{Fe}(\mathrm{CN})_{6}$ and SNAP were used to further confirm that the formation of adventitious root is mediated by NO. Obviously, 


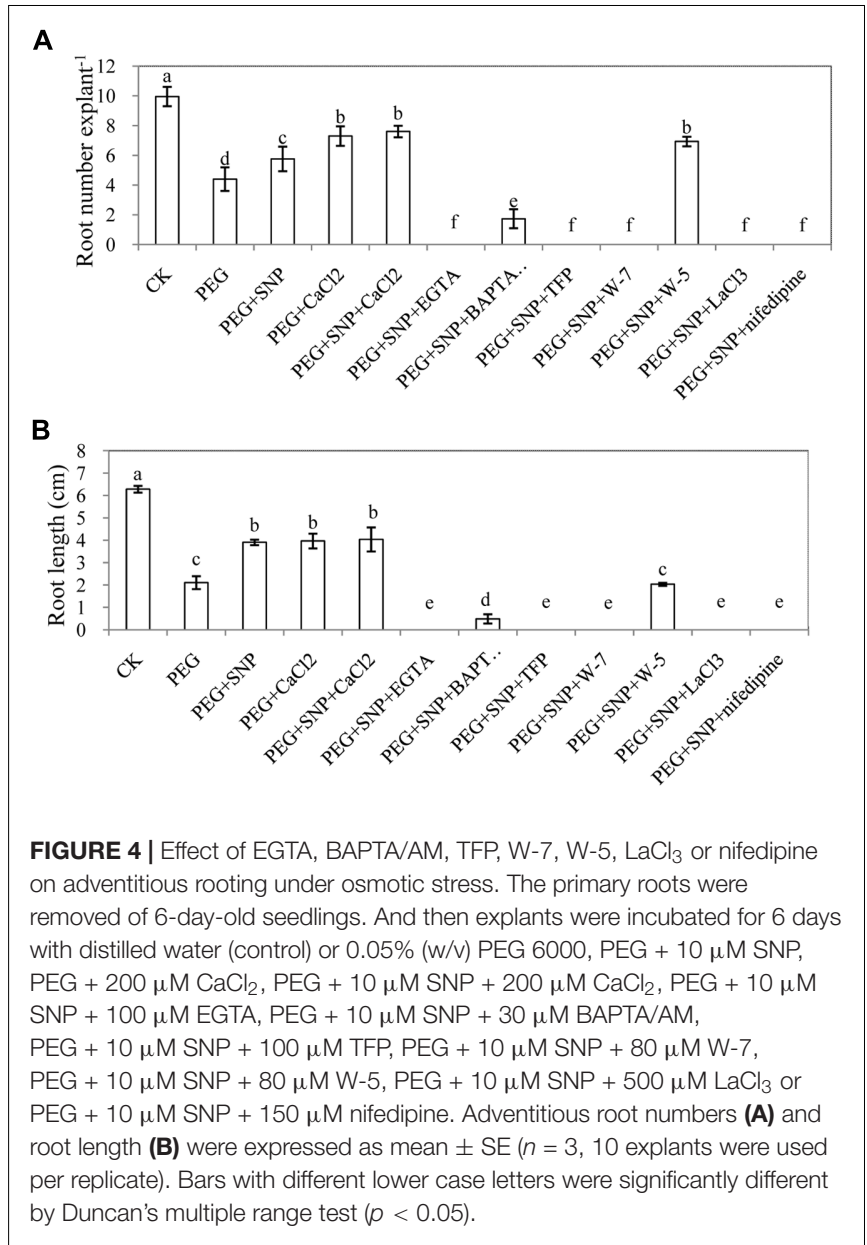

SNAP treatment promoted adventitious rooting under osmotic stress. These results implied that NO released from SNP or SNAP might be responsible for the enhancement of adventitious rooting under osmotic stress. In addition, cPTIO significantly reversed the promotive effects of $\mathrm{NO}$ on adventitious rooting (Figure 5 and Supplementary Figure S4).

\section{Fluorescence Intensity of $\mathrm{Ca}^{2+}$ in Hypocotyls during Adventitious Rooting under Osmotic Stress as Affected by SNP}

To investigate whether there is a link between $\mathrm{NO}$ and $\mathrm{Ca}^{2+}$ during adventitious rooting under osmotic stress, changes in fluorescence intensity of $\mathrm{Ca}^{2+}$ in hypocotyls were analyzed (Figures 6A,B and Supplementary Figures S5, S7). At 48 h, treatment with $\mathrm{PEG}+\mathrm{CaCl}_{2}$ in $\mathrm{Ca}^{2+}$ fluorescence intensity was significantly higher than that of PEG treatment alone. However, cPTIO, $\mathrm{NaN}_{3}$ or $\mathrm{Na}_{2} \mathrm{WO}_{4}$ treatments which may inhibit $\mathrm{NO}$ generation significantly impaired the fluorescence intensity of intracellular $\mathrm{Ca}^{2+}$ in cucumber hypocotyl at $48 \mathrm{~h}$. Besides, there was no significant difference between PEG treatment and $\mathrm{PEG}+\mathrm{NaNO}_{3}$ treatment. This gives an indication that $\mathrm{NO}$ plays a crucial role in increasing intracellular $\mathrm{Ca}^{2+}$ presence. Removing
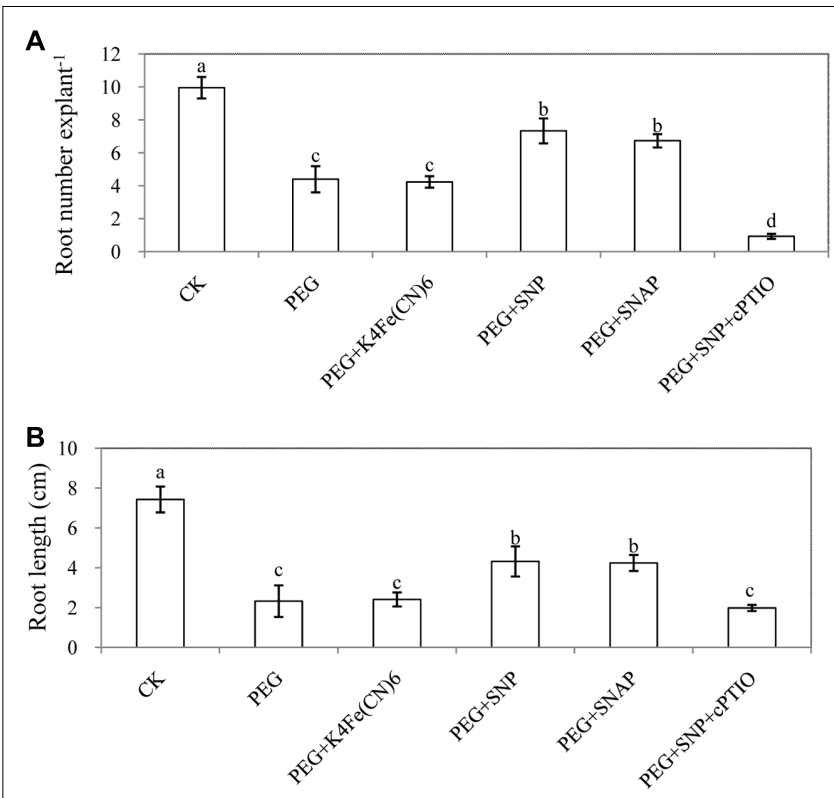

FIGURE 5 | Effect of $\mathrm{K}_{4} \mathrm{Fe}(\mathrm{CN})_{6}$, SNAP or CPTIO on adventitious rooting under osmotic stress. The primary roots were removed of 6 -day-old seedlings. And then explants were incubated for 6 days with distilled water (control) or $0.05 \%$ (w/v) PEG 6000, PEG + $50 \mu \mathrm{M} \mathrm{K}_{4} \mathrm{Fe}(\mathrm{CN})_{6}, \mathrm{PEG}+10 \mu \mathrm{M}$ SNP, PEG + $50 \mu \mathrm{M}$ SANP, PEG + $10 \mu \mathrm{M}$ SNP $+200 \mu \mathrm{M}$ cPTIO. Adventitious root numbers (A) and root length (B) were expressed as mean \pm SE $(n=3$, 10 explants were used per replicate). Bars with different lower case letters were significantly different by Duncan's multiple range test $(p<0.05)$.

endogenous $\mathrm{NO}$ decreased the level of intracellular $\mathrm{Ca}^{2+}$ which implied $\mathrm{NO}$ was responsible for the changes in intracellular $\mathrm{Ca}^{2+}$ during adventitious rooting under osmotic stress.

\section{Changes in Fluorescence Intensity of NO in Hypocotyls of Cucumber during Adventitious Rooting under Osmotic Stress}

In order to investigated the connection between $\mathrm{NO}$ and $\mathrm{Ca}^{2+}$ during adventitious rooting under osmotic stress, the level of NO fluorescent intensity was studied (Supplementary Figure S6). As shown in Figure 6C, at 48 h, PEG + SNP treatment enhanced the fluorescent intensity of NO production, compared to the control or PEG treatment. Meanwhile, the application of $\mathrm{CaCl}_{2}$ relatively increased the accumulation of endogenous NO in cucumber hypocotyl during the development of adventitious root under osmotic stress. The NO scavenger or inhibitor remarkably resulted in a reduction in fluorescence intensity of NO in cucumber. These results implied that there could be a relationship between the amount of endogenous NO and the process of adventitious rooting under osmotic stress.

\section{Effects of $\mathrm{NO}$ and $\mathrm{CaCl}_{2}$ on Leaf Water of Cucumber under Osmotic Stress}

Figure 7 showed that the value of leaf $\Psi_{\mathrm{w}}$ in PEG treatment is significantly lower than that of the control during adventitious 


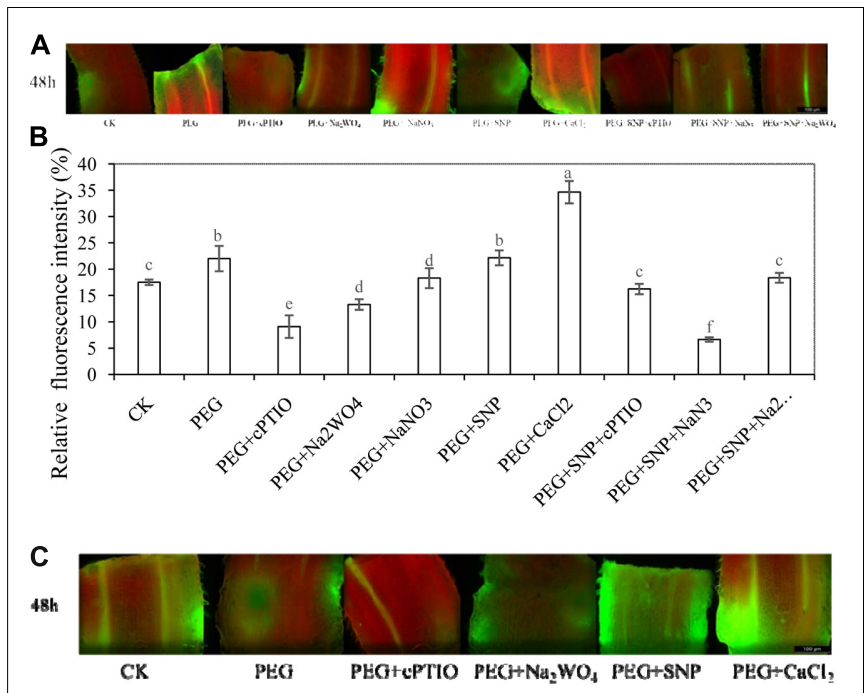

FIGURE 6 | Fluorescence intensity of $\mathrm{Ca}^{2+}$ or $\mathrm{NO}$ in hypocotyls of cucumber during adventitious rooting under osmotic stress. The primary roots were removed of 6-day-old seedlings. Intracellular $\mathrm{Ca}^{2+}$ fluorescence intensity in hypocotyls were treated with distilled water (control), 0.05\% (w/v) PEG 6000, $\mathrm{PEG}+200 \mu \mathrm{M}$ cPTIO, PEG + $100 \mu \mathrm{M} \mathrm{Na}_{2} \mathrm{WO}_{4}, \mathrm{PEG}+100 \mu \mathrm{M} \mathrm{NaNO}_{3}$, $\mathrm{PEG}+10 \mu \mathrm{M}$ SNP, PEG + $200 \mu \mathrm{M} \mathrm{CaCl}_{2}, \mathrm{PEG}+10 \mu \mathrm{M} \mathrm{SNP}+200 \mu \mathrm{M}$ $\mathrm{cPTIO}, \mathrm{PEG}+10 \mu \mathrm{M}$ SNP + $10 \mu \mathrm{M} \mathrm{NaN}_{3}$ or PEG + $10 \mu \mathrm{M} \mathrm{SNP}+100 \mu \mathrm{M}$ $\mathrm{Na}_{2} \mathrm{WO}_{4}$. NO fluorescence intensity in hypocotyls were treated with distilled water (control), 0.05\% (w/v) PEG 6000, PEG + $200 \mu \mathrm{M}$ cPTIO, PEG + $100 \mu \mathrm{M}$ $\mathrm{Na}_{2} \mathrm{WO}_{4}, \mathrm{PEG}+10 \mu \mathrm{M}$ SNP, PEG + $200 \mu \mathrm{MCaCl}_{2}$. Fluo-3/AM was utilized as the $\mathrm{Ca}^{2+}$-sensitive fluorescent probe. DAF-FM DA was utilized to detect endogenous NO of a longitudinal section from the tip of the hypocotyls. Changes in fluorescence intensity of $\mathrm{Ca}^{2+} \mathbf{( A )}$ was monitored by fluorescence microscope after $48 \mathrm{~h}$ and expressed as relative fluorescence intensity. The relative fluorescence intensity of intracellular $\mathrm{Ca}^{2+}(\mathbf{B})$ was analyzed by Image Pro software. Fluorescence intensity expressed as a percentage of control (B). Changes in fluorescence intensity of $\mathrm{NO}$ after $48 \mathrm{~h}$ of treatment in hypocotyls of cucumber during adventitious rooting under osmotic stress (C).

rooting at $48 \mathrm{~h}$. In addition, $\mathrm{PEG}+\mathrm{SNP}$ or $\mathrm{PEG}+\mathrm{CaCl}_{2}$ treatment significantly increased leaf $\Psi_{\mathrm{w}}$ in comparison to PEGtreated leaves only. At $48 \mathrm{~h}$, leaf $\Psi_{\mathrm{w}}$ of explants treated with PEG increased by $31.8 \%$ compared with the control. Application of $\mathrm{SNP}$ or $\mathrm{CaCl}_{2}$ remarkably increased the $\Psi_{\mathrm{W}}$ by $10.4 \%$, $55.0 \%$ in cucumber leaf, respectively, compared to that of PEG treatment alone. However, EGTA, BAPTA/AM, TFP, W-7, $\mathrm{LaCl}_{3}$ or nifedipine treatments resulted in a significant reduction in leaf $\Psi_{\mathrm{w}}$ during adventitious rooting under osmotic stress. This indicates that $\mathrm{Ca}^{2+}$ might be responsible for NO-mediated stress response during adventitious rooting in cucumber under osmotic stress.

\section{Effects of $\mathrm{NO}$ and $\mathrm{CaCl}_{2}$ on TBARS, $\mathrm{H}_{2} \mathrm{O}_{2}$ and $\mathrm{O}_{2}{ }^{-}$of Cucumber Leaf under Osmotic Stress}

As shown in Figure 8, PEG treatment significantly increased the concentration of TBARS, $\mathrm{H}_{2} \mathrm{O}_{2}$ and $\mathrm{O}_{2}{ }^{-}$. The level of reactive oxygen species (ROS) in $\mathrm{Ca}^{2+}$ chelators, $\mathrm{Ca}^{2+}$ channel inhibitors or CaM antagonist were significantly higher than those

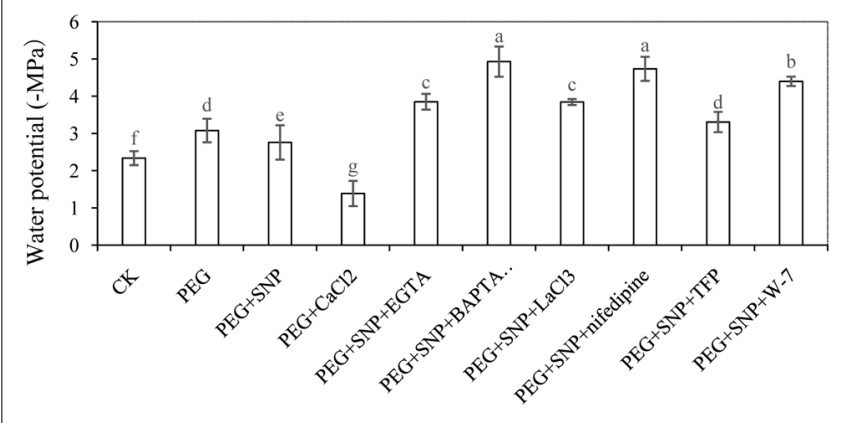

FIGURE 7 | Effects of $\mathrm{NO}$ and $\mathrm{CaCl}_{2}$ on leaf water of cucumber under osmotic stress. Explants were incubated with distilled water (control) or $0.05 \%$ (w/v) PEG 6000, PEG + $10 \mu \mathrm{M}$ SNP, PEG + $200 \mu \mathrm{M} \mathrm{CaCl}_{2}, \mathrm{PEG}+10 \mu \mathrm{M}$ $\mathrm{SNP}+100 \mu \mathrm{M}$ EGTA, PEG + $10 \mu \mathrm{M}$ SNP $+30 \mu \mathrm{M}$ BAPTA $/ \mathrm{M}$, $\mathrm{PEG}+10 \mu \mathrm{M} \mathrm{SNP}+500 \mu \mathrm{M} \mathrm{LaCl} 3, \mathrm{PEG}+10 \mu \mathrm{M} \mathrm{SNP}+150 \mu \mathrm{M}$ nifedipine, PEG + $10 \mu \mathrm{M}$ SNP $+100 \mu \mathrm{M}$ TFP or PEG $+10 \mu \mathrm{M}$ $\mathrm{SNP}+80 \mu \mathrm{M} \mathrm{W}-7$. Water potential of leaf in cucumber were determined after $48 \mathrm{~h}$ of treatment, respectively. Bars with different lower case letters were significantly different by Duncan's multiple range test $(p<0.05)$.

of PEG + SNP and PEG $+\mathrm{CaCl}_{2}$ treatments. At $48 \mathrm{~h}$, TBARS concentration with PEG treatment was $135.7 \%$ higher that of control (Figure 8A). However, the concentration of TBARS in $\mathrm{PEG}+\mathrm{SNP}$ and $\mathrm{PEG}+\mathrm{CaCl}_{2}$ treatments was significantly reduced by 66.9 and $48.2 \%$ compared to PEG treatment.

Figure 8B showed that $\mathrm{H}_{2} \mathrm{O}_{2}$ concentration with PEG + SNP and $\mathrm{PEG}+\mathrm{CaCl}_{2}$ treatments reduced by 23.3 and $36.6 \%$ at $48 \mathrm{~h}$, respectively, compared to PEG-treated explants. Conversely, the level of $\mathrm{H}_{2} \mathrm{O}_{2}$ in EGTA, BAPTA/AM, TFP, W-7, $\mathrm{LaCl}_{3}$ or nifedipine treatments was expressed at a higher level in comparison with $\mathrm{PEG}+\mathrm{SNP}$ and $\mathrm{PEG}+\mathrm{CaCl}_{2}$ treatments at $48 \mathrm{~h}$. The level of $\mathrm{O}_{2}{ }^{-}$treated with $\mathrm{PEG}$ was significantly enhanced with respect to the control (Figure 8C). In addition, a reduction of $\mathrm{O}_{2}{ }^{-}$content was observed under $\mathrm{PEG}+\mathrm{SNP}$ and $\mathrm{PEG}+\mathrm{CaCl}_{2}$ treatments at $48 \mathrm{~h}$, compared to that of PEG treatment. However, the accumulation of $\mathrm{O}_{2}{ }^{-}$content in $\mathrm{Ca}^{2+}$ chelators, $\mathrm{Ca}^{2+}$ channel inhibitors or $\mathrm{CaM}$ antagonist treatment remarkably increased at $48 \mathrm{~h}$.

\section{Effect of SNP and $\mathrm{CaCl}_{2}$ on the Activities of Antioxidant Enzymes during Adventitious Rooting under Osmotic Stress}

To further assess whether alleviation of osmotic stress is related to $\mathrm{NO}$ - or $\mathrm{CaCl}_{2}$-induced antioxidant defense, we measured the activity of antioxidant enzymes in cucumber explants during adventitious rooting under osmotic stress. The SOD activity in $\mathrm{PEG}+\mathrm{SNP}$ or $\mathrm{PEG}+\mathrm{CaCl}_{2}$ was increased by 28.3 and $26.4 \%$, respectively, compared to PEG treatment at $48 \mathrm{~h}$ (Figure 9A). Meanwhile, the CAT activity in PEG $+\mathrm{SNP}$ or $\mathrm{PEG}+\mathrm{CaCl}_{2}$ treatment at $48 \mathrm{~h}$ was 31.5 and $32.3 \%$ higher than that in osmotic stress alone (Figure 9B). Meanwhile, SNP, $\mathrm{CaCl}_{2}$ or $\mathrm{SNP}+\mathrm{CaCl}_{2}$ treatments resulted in a significant increase of APX activity under osmotic stress (Figure 9C). However, during the 

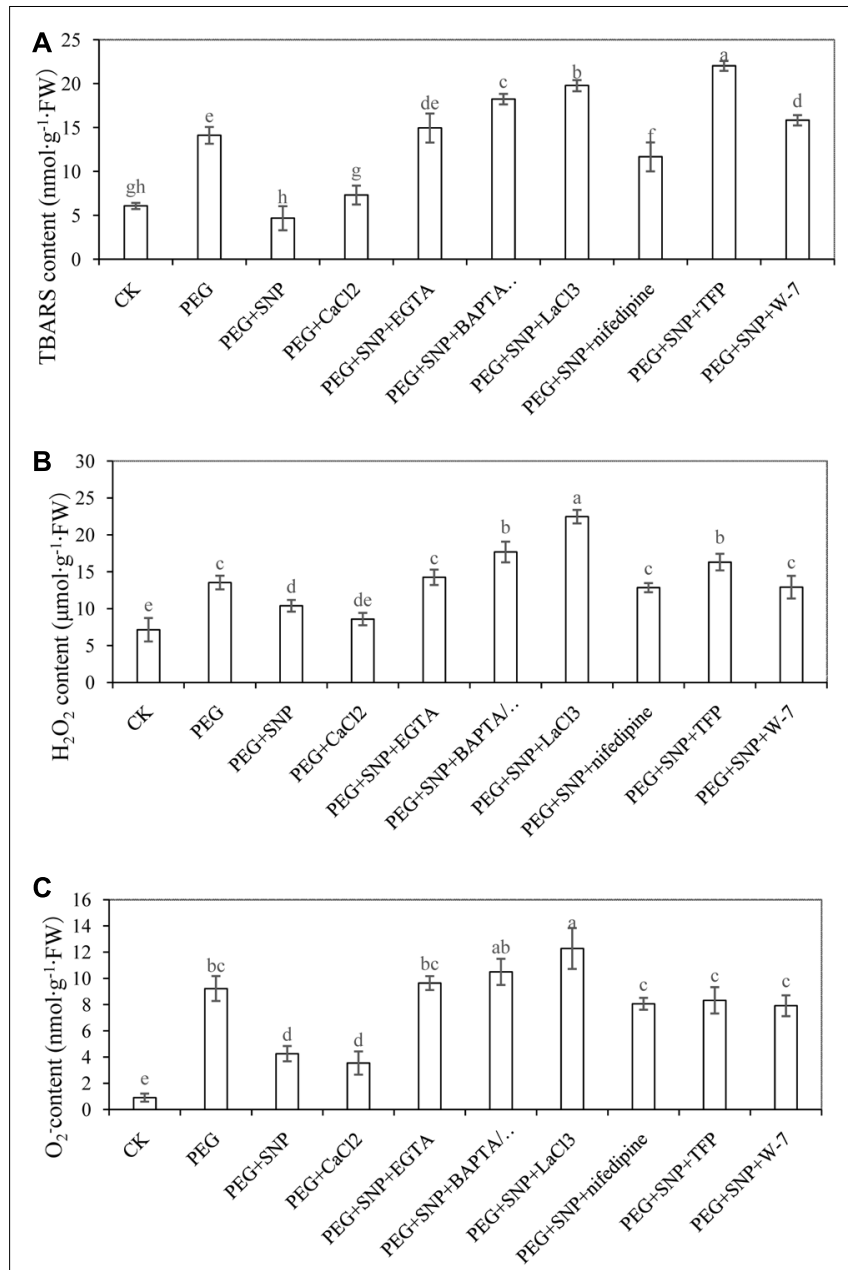

FIGURE 8 | Effects of $\mathrm{NO}$ and $\mathrm{CaCl}_{2}$ on TBARS (A), $\mathrm{H}_{2} \mathrm{O}_{2}$ (B) and $\mathrm{O}_{2}{ }^{-}$(C) of cucumber leaf under osmotic stress. Explants were incubated with distilled water (control) or $0.05 \%$ (w/v) PEG 6000, PEG + $10 \mu \mathrm{M}$ SNP, PEG + $200 \mu \mathrm{M}$ $\mathrm{CaCl}_{2}, \mathrm{PEG}+10 \mu \mathrm{M}$ SNP + $100 \mu \mathrm{M}$ EGTA, PEG + $10 \mu \mathrm{M} \mathrm{SNP}+30 \mu \mathrm{M}$ BAPTA/AM, PEG + $10 \mu \mathrm{M} \mathrm{SNP}+500 \mu \mathrm{M} \mathrm{LaCl} 3, \mathrm{PEG}+10 \mu \mathrm{M}$ SNP + $150 \mu \mathrm{M}$ nifedipine, $\mathrm{PEG}+10 \mu \mathrm{M}$ SNP + $100 \mu \mathrm{M}$ TFP or PEG + $10 \mu \mathrm{M}$ $\mathrm{SNP}+80 \mu \mathrm{M} \mathrm{W}-7$. The content of TBARS, $\mathrm{H}_{2} \mathrm{O}_{2}$ and $\mathrm{O}_{2}{ }^{-}$in cucumber were determined after $48 \mathrm{~h}$ of treatment, respectively. Bars with different lower case letters were significantly different by Duncan's multiple range test $(p<0.05)$.

development of adventitious root, EGTA, BAPTA/AM, TFP, W$7, \mathrm{LaCl}_{3}$ or nifedipine treatments significantly suppressed these antioxidant enzyme activities to levels lower than that of PEG treatment.

\section{Effects of SNP and $\mathrm{CaCl}_{2}$ on Photosynthetic System during Adventitious Rooting under Osmotic Stress \\ Chlorophyll Content}

Osmotic stress decreased chlorophyll content in our experiment (Figure 10). The chl a, chl b, chl $(\mathrm{a}+\mathrm{b})$ concentration in cucumber leaves from explants that were treated with in

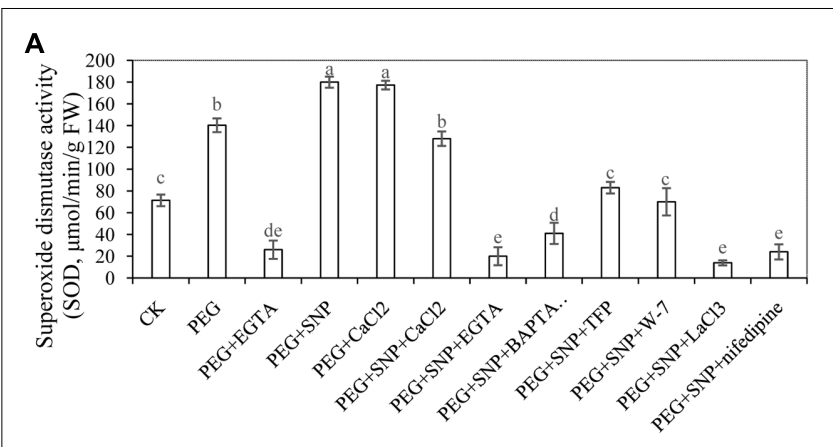

B

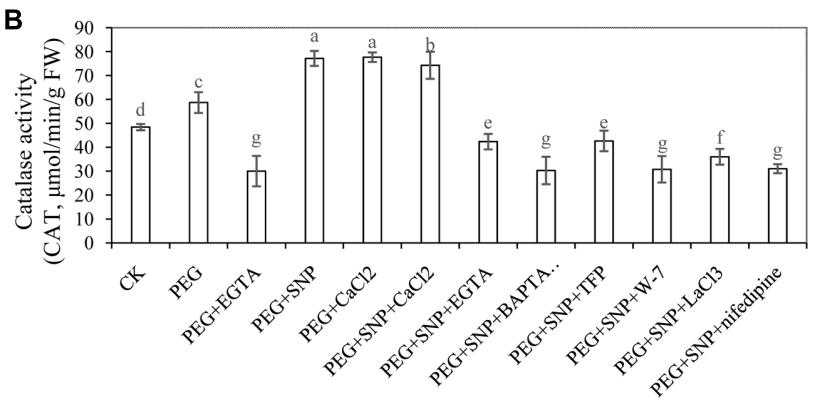

C

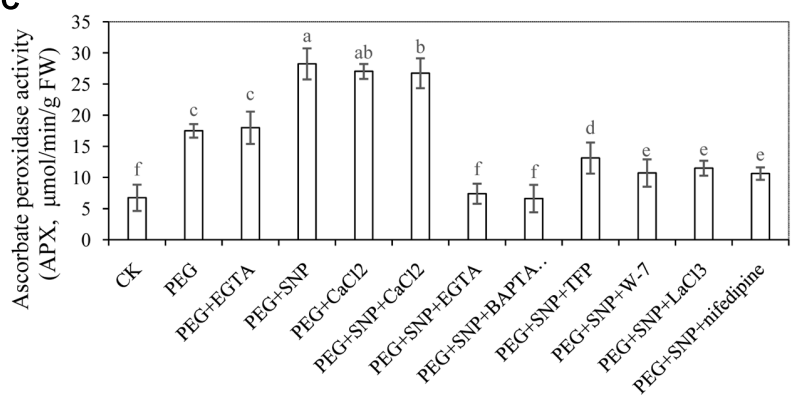

FIGURE 9 | Effects of SNP and $\mathrm{CaCl}_{2}$ on the activities of antioxidant enzymes during adventitious rooting under osmotic stress. Cucumber explants were incubated with distilled water (control) or $0.05 \%$ (w/v) PEG 6000,

PEG + $100 \mu \mathrm{M}$ EGTA, PEG + $10 \mu \mathrm{M}$ SNP, PEG + $200 \mu \mathrm{M} \mathrm{CaCl}_{2}$, $\mathrm{PEG}+10 \mu \mathrm{M} \mathrm{SNP}+200 \mu \mathrm{M} \mathrm{CaCl}_{2}, \mathrm{PEG}+10 \mu \mathrm{M} \mathrm{SNP}+100 \mu \mathrm{M}$ EGTA, $\mathrm{PEG}+10 \mu \mathrm{M}$ SNP + $30 \mu \mathrm{M}$ BAPTAVAM, PEG + $10 \mu \mathrm{M}$ SNP + $100 \mu \mathrm{M}$ TFP, $\mathrm{PEG}+10 \mu \mathrm{M} \mathrm{SNP}+80 \mu \mathrm{M} \mathrm{W}-7, \mathrm{PEG}+10 \mu \mathrm{M} \mathrm{SNP}+500 \mu \mathrm{M} \mathrm{LaCl} 3$ or $\mathrm{PEG}+10 \mu \mathrm{M} \mathrm{SNP}+150 \mu \mathrm{M}$ nifedipine. Activities of SOD (A), CAT (B) and APX (C) were determined at $48 \mathrm{~h}$ of treatment, respectively. Bars with different lower case letters were significantly different by Duncan's multiple range test $(p<0.05)$.

$\mathrm{SNP}, \mathrm{Ca}^{2+}$ or $\mathrm{SNP}+\mathrm{CaCl}_{2}$ treatments significantly increased, compared with those from PEG and PEG + EGTA treatment. These results suggested that application of $\mathrm{NO}$ or $\mathrm{CaCl}_{2}$ was more effective in retarding the loss of chlorophyll and in improving photochemistry under osmotic stress. However, EGTA, BAPTA/AM, TFP, $\mathrm{W}-7, \mathrm{LaCl}_{3}$ and nifedipine treatments decreased the level of chl $a$, chl $b$ and chl $(a+b)$, compared to explant exposed to SNP, $\mathrm{CaCl}_{2}$ or $\mathrm{SNP}+\mathrm{CaCl}_{2}$ treatments. Meanwhile, the concentrations of chl a, chl b, chl $(\mathrm{a}+\mathrm{b})$ in explants treated with EGTA, BAPTA/AM, TFP, W-7, $\mathrm{LaCl}_{3}$ and nifedipine were significantly lower than those of PEG treatment which indicated that $\mathrm{Ca}^{2+} / \mathrm{CaM}$ might 


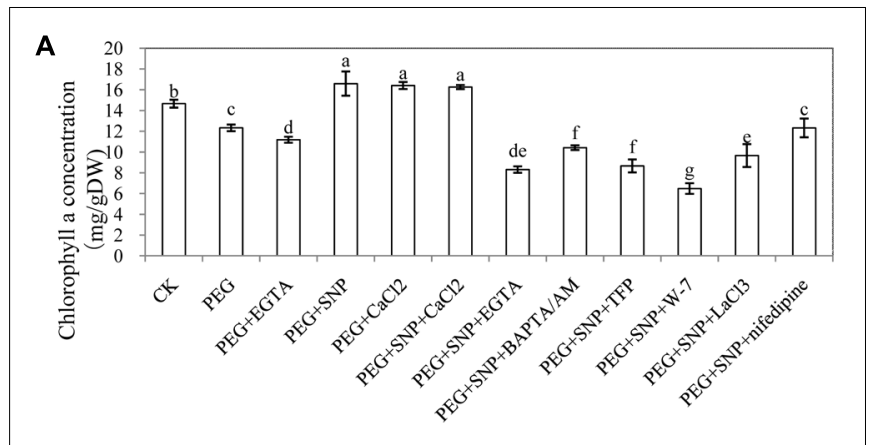

B

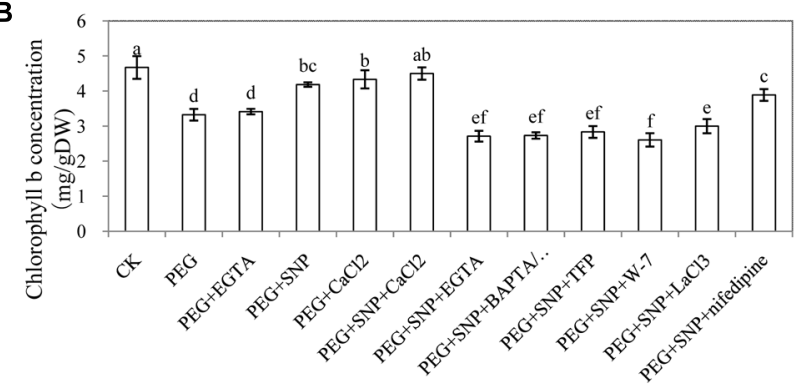

C

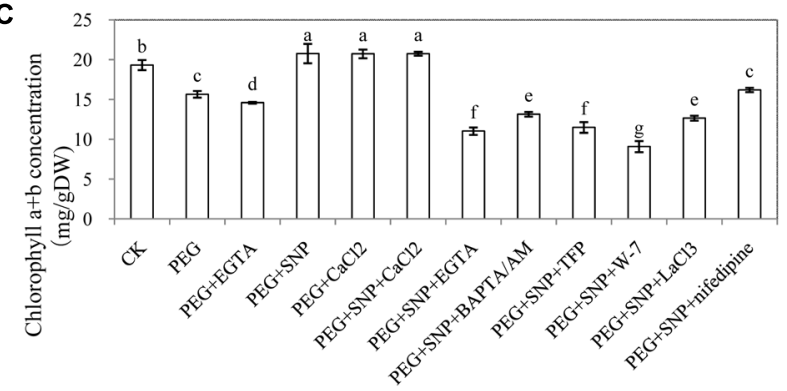

FIGURE 10 | Effects of $\mathrm{NO}$ and $\mathrm{CaCl}_{2}$ on chlorophyll content of cucumber leaf under osmotic stress. Explants were incubated with distilled water (control) or 0.05\% (w/v) PEG 6000, PEG + $100 \mu \mathrm{M}$ EGTA, PEG + $10 \mu \mathrm{M}$ SNP, $\mathrm{PEG}+200 \mu \mathrm{M} \mathrm{CaCl}_{2}, \mathrm{PEG}+10 \mu \mathrm{M} \mathrm{SNP}+200 \mu \mathrm{M} \mathrm{CaCl}_{2}, \mathrm{PEG}+10 \mu \mathrm{M}$ SNP + $100 \mu \mathrm{M}$ EGTA, PEG + $10 \mu \mathrm{M}$ SNP + $30 \mu \mathrm{M}$ BAPTA AM,

$\mathrm{PEG}+10 \mu \mathrm{M} \mathrm{SNP}+100 \mu \mathrm{M}$ TFP, PEG $+10 \mu \mathrm{M} \mathrm{SNP}+80 \mu \mathrm{M} \mathrm{W}-7$, $\mathrm{PEG}+10 \mu \mathrm{M} \mathrm{SNP}+500 \mu \mathrm{M} \mathrm{LaCl} 3$ or PEG $+10 \mu \mathrm{M} \mathrm{SNP}+150 \mu \mathrm{M}$ nifedipine. Leaf chlorophyll a (A), chlorophyll b (B) and chlorophyll a+b (C) content was measured after $48 \mathrm{~h}$ of treatment. The values (mean \pm SE) are the average of three independent experiments. Bars with different lower case letters were significantly different by Duncan's multiple range test $(p<0.05)$.

be involved in NO-regulating the increases in chlorophyll content.

\section{Effect of SNP or $\mathrm{CaCl}_{2}$ on Photochemistry under Osmotic Stress}

Compared to the control, PEG and PEG + EGTA treatment decreased the value of Fv/Fm (Table 1). However, SNP treatment or $\mathrm{CaCl}_{2}$ treatment increased $\mathrm{Fv} / \mathrm{Fm}$ by 9.2 and $8.2 \%$ higher than that of control, respectively. Moreover, EGTA, BAPTA/AM, TFP or W-7 treatments resulted in 12.6, 15.5, 14.1, and $14.6 \%$ reduction in $\mathrm{Fv} / \mathrm{Fm}$, respectively, compared to osmotic stress. $\mathrm{LaCL}_{3}$ and nifedipine treatment significantly reduced $\mathrm{Fv} / \mathrm{Fm}$ by 46.4 and $37.9 \%$, respectively, compared to that of PEG + SNP treatment. In addition, the effect of different treatments on ФPSII and $\mathrm{qP}$ were similar to that of $\mathrm{Fv} / \mathrm{Fm}$ (Table 1). PEG treatment significantly increased NPQ compared with control. However, $\mathrm{PEG}+\mathrm{SNP}$ or PEG $+\mathrm{CaCl}_{2}$ treatments significantly decreased NPQ. There was a significant increase in NPQ level after removing the endogenous $\mathrm{Ca}^{2+} / \mathrm{CaM}$. These results implied that $\mathrm{NO}$ or $\mathrm{Ca}^{2+}$ had a positive role in improving the development of adventitious root by regulating chlorophyll florescent parameters.

\section{DISCUSSION}

Previous studies have indicated that $\mathrm{NO}$ and $\mathrm{Ca}^{2+}$, as signaling molecules, might be involved in plants response to abiotic stress (Shan et al., 2015; Zou et al., 2015; Silveira et al., 2017a). However, whether there is a relationship between $\mathrm{NO}$ and $\mathrm{Ca}^{2+} / \mathrm{CaM}$ in the development of adventitious root under osmotic stress has not received the needed research attention. In this study, we have found that $\mathrm{Ca}^{2+} / \mathrm{CaM}$ interactions were involved in NO-induced adventitious rooting process in cucumber under osmotic stress.

\section{Actions and Relationships between NO and $\mathrm{Ca}^{2+}$ on Promoting Adventitious Rooting under Osmotic Stress}

The number and length of adventitious roots in cucumber was retarded by different concentrations of PEG treatment. However, when exogenous SNP or $\mathrm{CaCl}_{2}$ were applied under osmotic stress, root number and length was significantly increased to levels higher than those of PEG treatment (Figures 2, 3). According to previous report, NO promoted adventitious root formation in marigold under drought stress (Liao et al., 2012a). $\mathrm{Ca}^{2+}$ was also found to have induced the adventitious rooting

TABLE 1 | Effects of SNP or $\mathrm{CaCl}_{2}$ on photochemistry under osmotic stress.

\begin{tabular}{|c|c|c|c|c|}
\hline Treatments & Fv/Fm & ФPSII & $\mathrm{qP}$ & NPQ \\
\hline CK & $0.783 d$ & $0.597 \mathrm{c}$ & $0.647 i$ & 0.4671 \\
\hline PEG & $0.683 e$ & $0.533 d$ & $0.583 \mathrm{e}$ & $0.713 f$ \\
\hline$P E G+E G T A$ & $0.630 f$ & $0.452 \mathrm{~g}$ & $0.498 j$ & $0.668 \mathrm{~h}$ \\
\hline PEG + SNP & $0.855 a$ & $0.667 a$ & $0.723 a$ & $0.527 i$ \\
\hline $\mathrm{PEG}+\mathrm{CaCl}_{2}$ & $0.847 \mathrm{~b}$ & $0.653 b$ & $0.717 b$ & $0.520 \mathrm{j}$ \\
\hline $\mathrm{PEG}+\mathrm{SNP}+\mathrm{CaCl}_{2}$ & $0.827 c$ & $0.653 b$ & $0.703 c$ & $0.517 \mathrm{k}$ \\
\hline$P E G+S N P+E G T A$ & $0.597 \mathrm{~g}$ & $0.463 e$ & $0.503 d$ & $0.757 b$ \\
\hline PEG + SNP + BAPTAVAM & $0.577 \mathrm{k}$ & $0.447 \mathrm{~h}$ & $0.513 f$ & $0.767 a$ \\
\hline $\mathrm{PEG}+\mathrm{SNP}+\mathrm{TFP}$ & $0.587 i$ & $0.453 f$ & $0.507 \mathrm{~h}$ & $0.747 \mathrm{e}$ \\
\hline$P E G+S N P+W-7$ & $0.583 j$ & $0.437 i$ & $0.508 \mathrm{~g}$ & $0.750 d$ \\
\hline $\mathrm{PEG}+\mathrm{SNP}+\mathrm{LaCl}_{3}$ & $0.558 \mid$ & $0.350 \mathrm{k}$ & $0.396 k$ & $0.671 \mathrm{~g}$ \\
\hline PEG + SNP + nifedipine & $0.591 \mathrm{~h}$ & $0.413 j$ & 0.3041 & $0.755 c$ \\
\hline
\end{tabular}

Explants were incubated with distilled water (control) or 0.05\% (W/V) PEG 6000, PEG + $100 \mu \mathrm{M}$ EGTA, PEG + $10 \mu \mathrm{M}$ SNP, PEG + $200 \mu \mathrm{M} \mathrm{CaCl}_{2}, P E G+10 \mu \mathrm{M}$ $S N P+200 \mu \mathrm{M} \mathrm{CaCl}_{2}$, PEG + $10 \mu \mathrm{M}$ SNP + $100 \mu \mathrm{M}$ EGTA, PEG + $10 \mu \mathrm{M}$ SNP + $30 \mu M$ BAPTAVAM, PEG + $10 \mu \mathrm{M}$ SNP + $100 \mu \mathrm{M}$ TFP, PEG + $10 \mu \mathrm{M}$ $S N P+80 \mu M W-7, P E G+10 \mu M S N P+500 \mu M L^{2} a l_{3}$ or PEG + $10 \mu M$ $S N P+150 \mu M$ nifedipine. Parameters of chlorophyll fluorescence with different treatments were conducted after $48 \mathrm{~h}$ of treatment. Values followed by a different lower-case letter in the same column were significantly different by Duncan's multiple range test at $p<0.05$. 
process in marigold explants under normal condition (Liao et al., 2012b). According to our results (Figures 2, 3), SNP or $\mathrm{Ca}^{2+}$ had the dose-dependent effect on induction of adventitious rooting in cucumber under osmotic stress. In addition, results from $\mathrm{PEG}+\mathrm{K}_{4} \mathrm{Fe}(\mathrm{CN})_{6}, \mathrm{PEG}+\mathrm{SNAP}$ and $\mathrm{PEG}+\mathrm{SNP}+\mathrm{cPTIO}$ treatments further confirmed the role of $\mathrm{NO}$ released from SNP and SNAP (Figure 5). These results indicated that suitable dosages of $\mathrm{NO}$ or $\mathrm{Ca}^{2+}$ might alleviate the injury due to osmotic stress on adventitious rooting. Previous researches have suggested that $\mathrm{NO}$ or $\mathrm{Ca}^{2+}$ played critical roles in enhancing stress resistance through mediating antioxidant defense system, protecting the structure of cell membrane and chlorophyll function as well as maintaining ion homeostasis in plants (Shan et al., 2015; Zou et al., 2015; Li et al., 2016). Recently, the crosstalk between $\mathrm{NO}$ and $\mathrm{Ca}^{2+}$ under abiotic stress in plants was reported. For example, NO might mediate $\mathrm{Ca}^{2+}$ regulated antioxidant enzymes activities to respond against high irradiance -induced oxidative stress (Xu et al., 2016). Similarly, Lang et al. (2014) investigated the functional relationship between $\mathrm{NO}$ and $\mathrm{Ca}^{2+}$ mediating root ion fluxes under salt stress. In another experiment with explants treated with EGTA, BAPTM/AM, $\mathrm{LaCl}_{3}$, nifedipine, TFP and $\mathrm{W}-7$, the formation of $\mathrm{NO}$-induced adventitious root was significantly retarded under osmotic stress (Figure 4). These results revealed that inhibition of endogenous $\mathrm{Ca}^{2+} / \mathrm{CaM}$ might completely inhibit the NOinduced adventitious rooting under osmotic condition. Previous study on rice indicated that $\mathrm{Ca}^{2+}$ was involved in NO-induced lateral root formation (Chen and $\mathrm{Kao}, 2012$ ) and $\mathrm{Ca}^{2+}$ inhibitors (EGTA and BAPTA/AM) or CaM antagonists (TFP and W7) were found to have suppressed the positive effects of NO and $\mathrm{H}_{2} \mathrm{O}_{2}$ on adventitious rooting of marigold under stressfree condition (Liao et al., 2012a). Additionally, Lanteri et al. (2006) also found that $\mathrm{Ca}^{2+}$ might be involved in NO- or auxin-induced adventitious root formation through activating CDPK activity and the application of $\mathrm{Ca}^{2+}$ channel inhibitors significantly suppressed NO- and IAA-induced development of adventitious rooting which indicated that $\mathrm{Ca}^{2+}$ is required for the adventitious rooting process. Our results further revealed that $\mathrm{Ca}^{2+} / \mathrm{CaM}$ played an essential role in $\mathrm{NO}$-induced adventitious rooting under abiotic stress. $\mathrm{Ca}^{2+} / \mathrm{CaM}$ might be a downstream signaling in the $\mathrm{NO}$-induced adventitious rooting under osmotic stress.

The application of SNP elevated intracellular $\mathrm{Ca}^{2+}$ in cucumber hypocotyls under osmotic stress which indicated that the promotive effect of NO under osmotic stress was dependent on increasing the production of $\mathrm{Ca}^{2+}$ in plant cell. Abdul-Awal et al. (2016) reported that NO could mediate increases of $\left[\mathrm{Ca}^{2+}\right]$ cyt through activity of ADP-Ribosyl Cyclase in Arabidopsis. Ma et al. (2008) also suggested that NO synthesis might be activated by $\mathrm{Ca}^{2+}$ through CaMs in Arabidopsis. These studies suggested that $\mathrm{NO}$ and $\mathrm{Ca}^{2+}$ may modulate each other's level to regulate the plant developmental and physiological processes. In our study, $\mathrm{SNP}+\mathrm{cPTIO}, \mathrm{SNP}+\mathrm{NaN}_{3}$ and $\mathrm{SNP}+\mathrm{Na}_{2} \mathrm{WO}_{4}$ significantly inhibited the level of endogenous $\mathrm{Ca}^{2+}$ during adventitious root formation (Figures 6A,B). In addition, treatment with PEG + cPTIO or PEG $+\mathrm{Na}_{2} \mathrm{WO}_{4}$ significantly decreased the production of endogenous $\mathrm{Ca}^{2+}$ in hypocotyl as well. Therefore, $\mathrm{Ca}^{2+}$ might be as downstream of $\mathrm{NO}$ in the development of adventitious root under osmotic stress. In previous studies, hydrogen gas $\left(\mathrm{H}_{2}\right)$ (Zhu et al., 2016), carbon monoxide (CO) (Chen et al., 2017) and $\mathrm{H}_{2} \mathrm{O}_{2}$ (Xuan et al., 2008; Yang et al., 2013) were also suggested to be involved in plants adventitious rooting. These signaling molecules may mediate each other through activation of receptors or targeted protein to affect the process of adventitious rooting in plants. Additionally, Endogenous NO might accumulate during the development of adventitious root (Figure 6C). Previous studies showed that $\mathrm{NO}$ could be an essential signaling molecule to regulate the development and growth of adventitious roots in plants (Lanteri et al., 2008; Liao et al., 2012a). Pagnussat et al. (2002) also suggested that NO might be involved in auxin-induced adventitious root formation through transient $\mathrm{NO}$ accumulation in cucumber explants. These results indicated that NO is responsible for the adventitious root organogenesis. Silveira et al. (2017a) found that drought-tolerant sugarcane genotype could accumulate more NO than the sensitive one, suggesting that there might exist an association between droughttolerance and NO production and metabolism. Interestingly, $\mathrm{CaCl}_{2}$ treatment also increased the content of endogenous $\mathrm{NO}$ as well which implied that there might be a close interplay between $\mathrm{NO}$ and $\mathrm{Ca}^{2+}$ during the development of adventitious roots in cucumber under stress condition.

\section{Activation of Antioxidative Response during Adventitious Rooting under Osmotic Stress}

An increase in the ROS level might induce membrane lipid peroxidation in cells (Panyuta et al., 2016). In order to investigate the effects of SNP and $\mathrm{CaCl}_{2}$ on the development of adventitious root under osmotic stress, the changes in TBARS in cucumber explants were analyzed. At $48 \mathrm{~h}$, PEG treatment significantly enhanced the concentration of TBARS in comparison with the control (Figure 8A), which implied that osmotic stress might induce the accumulation of TBARS (Jaleel et al., 2007). In addition, $\mathrm{PEG}+\mathrm{SNP}$ and $\mathrm{PEG}+\mathrm{CaCl}_{2}$ treatments significantly reduced the content of TBARS compared to PEG treatment (Figure 8A). Previous study showed NO could protect sunflower leaves under Cd-induced oxidative stress by decreasing TBARS content (Laspina et al., 2005). Besides, Larkindale and Knight (2002) also suggested that inhibiting the endogenous $\mathrm{Ca}^{2+}$ content could increase the oxidative damage under heat stress by increasing the TBARS content in Arabidopsis. Our results showed that the application of $\mathrm{SNP}$ or $\mathrm{CaCl}_{2}$ significantly decrease TBARS content in cucumber explant under osmotic stress (Figure 8A). However, the TBARS content of EGTA, BAPTA/AM, TFP, W-7, $\mathrm{LaCl}_{3}$ or nifedipine treatments were significantly higher than those of $\mathrm{SNP}$ or $\mathrm{CaCl}_{2}$ treatments. These results indicated that removal of endogenous $\mathrm{Ca}^{2+}$ during NO-induced adventitious rooting under osmotic stress probably increased the level of membrane lipid peroxidation, hence, aggravated oxidative stress and caused cell death or the decrease of relative antioxidant enzymes activities (Liu et al., 2013; Chen et al., 2015). 
$\mathrm{H}_{2} \mathrm{O}_{2}$ or $\mathrm{O}_{2}{ }^{-}$, which was a form of ROS, also caused oxidative damage in plants under stressful condition (Romero-Puertas et al., 2004; Cho and Seo, 2005). Wang and Yang (2005) found that SNP pre-treatment significantly inhibited the generation of $\mathrm{O}_{2}{ }^{-}$and $\mathrm{H}_{2} \mathrm{O}_{2}$ in the roots of Cassia tora $\mathrm{L}$ under Aluminum (Al) stress. Another research also found that there is a reduction in the content of $\mathrm{H}_{2} \mathrm{O}_{2}$, TBARS and other ROS in $\mathrm{CaCl}_{2}$ treatment in soybean seedlings under salt stress (Arshi et al., 2010). Our results showed that SNP or $\mathrm{CaCl}_{2}$ treatments under osmotic stress significantly reduced the production of $\mathrm{H}_{2} \mathrm{O}_{2}$ or $\mathrm{O}_{2}{ }^{-}$during the process of adventitious root development (Figures 8B,C). However, the application of $\mathrm{Ca}^{2+}$ chelators, $\mathrm{Ca}^{2+}$ channel inhibitors or $\mathrm{CaM}$ antagonist might keep a higher level $\mathrm{H}_{2} \mathrm{O}_{2}$ or $\mathrm{O}_{2}{ }^{-}$content than those of $\mathrm{SNP}$ or $\mathrm{CaCl}_{2}$ treatment. These findings also suggest that $\mathrm{NO}$ or $\mathrm{Ca}^{2+}$ might reverse the damage of osmotic stress during adventitious rooting by blocking the generation of ROS in cucumber explants.

There are several reports that $\mathrm{NO}$ or $\mathrm{Ca}^{2+}$ might have the capacity to regulate the antioxidant system by increasing the activities of antioxidant enzymes under various stresses (Shi K. et al., 2015; Zou et al., 2015; Silveira et al., 2017b). Our results showed that $\mathrm{SNP}, \mathrm{CaCl}_{2}$ or $\mathrm{SNP}+\mathrm{CaCl}_{2}$ treatment significantly increased the activities of antioxidant enzymes during the development of adventitious root under osmotic stress. SOD, CAT and APX activities in cucumbers treated with SNP, $\mathrm{CaCl}_{2}$ or SNP $+\mathrm{CaCl}_{2}$ were higher than those of PEG treatment (Figure 9). Li et al. (2016) suggested that $\mathrm{Ca}^{2+}$ could alleviate the inhibition of $\mathrm{Cd}$ on the root growth by reducing oxidative injuries which indicated that there could be a relationship between the root growth and oxidative system. Moreover, El-Shabrawi et al. (2010) also found that there was a positive relationship between increased antioxidant defense mechanism and the reduction of oxidative damage. The increased activities of antioxidant enzymes increased oxidation resistance by decreasing ROS generation rate during adventitious rooting process.

\section{Enhancement of Water Retention and Photosynthetic Activity under Osmotic Stress}

In order to confirm the influence of PEG-induced osmotic stress, leaf $\Psi_{\mathrm{w}}$ in cucumber was determined in our experiment (Figure 7). Previous study found that $\mathrm{Cd}$ might decrease leaf $\Psi_{\mathrm{w}}$ and relative water content (RWC) in bean plants (Barcelo et al., 1986). Wilson et al. (2014) also suggested that plastid osmotic stress might significantly decreased water potential in Arabidopsis. In our study, greater reduction in leaf $\Psi_{\mathrm{w}}$ was observed with PEG treatment compared to the control (Figure 7). The leaf $\Psi_{\mathrm{w}}$ was significantly increased by exogenous supplied SNP or $\mathrm{CaCl}_{2}$ under osmotic stress. Recent research suggested NO might alleviate water deficit stress through increasing leaf $\Psi_{\mathrm{w}}$ and RWC in Cakile maritima (Jday et al., 2016). Our results indicated that application of exogenous NO might increase the water potential in cucumber under stress condition to alleviate the damage of osmotic stress during adventitious rooting. Meanwhile, inhibition of endogenous $\mathrm{Ca}^{2+}$ accumulation might reverse the positive effect of NO on alleviating the osmotic damage during the development of adventitious root in cucumber.

Górnik et al. (2008) found that drought stress reduced chlorophyll content in the leaves during rooting of grapevine cuttings. In addition, Humphries and Thorne (1964) suggested that photosynthesis was retarded when root growth was restricted by application of kinetin. These results imply that there is a link between photosynthesis and rooting. Uchida et al. (2002) found that suitable concentration of NO restored the chlorophyll levels in rice leaves and protected photosystem II (PSII) to maintain a relatively high activity under salt and heat stresses. Also, Silveira et al. (2016) indicated that exogenous NO might improve photosynthesis under water deficit and Tiwari et al. (2016) noticed that $\mathrm{Ca}^{2+}$ application alleviated the reduction of chl a under heat stress. The application of $\mathrm{CaCl}_{2}$ enhanced photosynthesis by increasing the contents of chl a, chl b, and $\mathrm{chl}(\mathrm{a}+\mathrm{b})$ in Zoysia japonica under drought stress (Xu et al., 2013). In our study, the content of chl a, chl b, or chl (a + b) in cucumbers treated with PEG was significantly lower than those of control, while application of SNP or $\mathrm{CaCl}_{2}$ under osmotic stress increased the concentrations of chl a, chl b, or chl $(a+b)$ to levels higher than PEG treatment alone (Figure 10). These findings indicated that $\mathrm{NO}$ or $\mathrm{CaCl}_{2}$ treatment might significantly prevent the degradation of chlorophyll in cucumber in order to promote photosynthesis during adventitious rooting under osmotic stress. The EGTA, BAPTA/AM, TFP, W-7, $\mathrm{LaCl}_{3}$ and nifedipine, however, caused significant degradation of chlorophyll content in the leaves. It has been reported that abiotic stress led to decreases in photosynthetic rates by affecting chlorophyll fluorescence parameters in plants (Hou et al., 2016). In our study, PEG treatment significantly decreased the value of $\mathrm{Fv} / \mathrm{Fm}$, ФPSII or qP but increased NPQ. However, SNP or $\mathrm{CaCl}_{2}$ treatment increased $\mathrm{Fv} / \mathrm{Fm}$, ФPSI or qP which implied that $\mathrm{NO}$ or $\mathrm{CaCl}_{2}$ could reduce damage to photosynthesis under osmotic stress, maintaining the photochemical activity. Zhang et al. (2012) found that NO alleviated iron-deficiency in peanut leaves via increasing $\mathrm{Fv} / \mathrm{Fm}$ and $\Phi$ PSII which suggested that NO had a protective effect on photosystem II (PSII) in plants. In addition, Zhao and Tan (2005) reported that exogenous $\mathrm{Ca}^{2+}$ also played a crucial role in protecting photochemistry in wheat plants under heat and high irradiance stresses. However, EGTA or $\mathrm{LaCl}_{3}$ treatment had the opposite effect which indicated that endogenous $\mathrm{Ca}^{2+}$ might be involved in mediating photosynthesis in wheat. These results indicated that there might be a positive relationship between adventitious rooting and photosynthetic level. Besides, $\mathrm{Ca}^{2+}$ might be a downstream molecule involved in NO-induced formation of photosynthetic pigments and increases of photochemical activity in order to promote adventitious rooting under osmotic stress.

\section{CONCLUSION}

The results of our experiments have shown that exogenous application of $\mathrm{NO}$ and $\mathrm{CaCl}_{2}$ alleviated osmotic stress and 
promoted the development of adventitious roots in cucumber under stressful conditions. Our data also revealed that $\mathrm{Ca}^{2+} / \mathrm{CaM}$ might be downstream molecules of $\mathrm{NO}$ signaling pathway, protecting photosynthetic system and stimulating the antioxidant defense system. As there is a complex interaction between $\mathrm{NO}$ and $\mathrm{Ca}^{2+} / \mathrm{CaM}$ in the adventitious rooting process under abiotic stress, further work should focus on the molecular mechanism of the crosstalk between NO and $\mathrm{Ca}^{2+} / \mathrm{CaM}$ during signaling transduction under various stresses.

\section{AUTHOR CONTRIBUTIONS}

WL designed the experiments; $\mathrm{LN}$ and JY performed the experiments; WL, LN, and MZ performed data analysis; WL, LN, and JY wrote the manuscript; WL, JhY, and MD edited the manuscript.

\section{REFERENCES}

Abdul-Awal, S. M., Hotta, C. T., Davey, M. P., Dodd, A. N., Smith, A. G., and Webb, A. A. (2016). NO-mediated [Ca2+] cyt increases depend on ADP-ribosyl cyclase activity in Arabidopsis. Plant Physiol. 171, 623-631. doi: 10.1104/pp.15. 01965

Aebi, H. (1984). Catalase in vitro. Methods Enzymol. 105, 121-126. doi: 10.1016/ S0076-6879(84)05016-3

Arnon, D. I. (1949). Copper enzymes in isolated chloroplasts. Polyphenol oxidase in Beta vulgaris. Plant Physiol. 24, 1-15. doi: 10.1104/pp.24.1.1

Arshi, A., Ahmad, A., Aref, I. M., and Iqbal, M. (2010). Calcium interaction with salinity-induced effects on growth and metabolism of soybean (Glycine max L.) cultivars. J. Environ. Biol. 31, 795-801.

Barcelo, J., Poschenrieder, C., Andreu, I., and Gunse, B. (1986). Cadmium-induced decrease of water stress resistance in bush bean plants (Phaseolus vulgaris L. cv. Contender) I. Effects of Cd on water potential, relative water content, and cell wall elasticity. J. Plant Physiol. 125, 17-25. doi: 10.1016/S0176-1617(86) 80239-5

Beligni, M. V., and Lamattina, L. (2000). Nitric oxide stimulates seed germination and de-etiolation, and inhibits hypocotyl elongation, three light-inducible responses in plants. Planta 210, 215-221. doi: 10.1007/PL00008128

Búfalo, J., Rodrigues, T. M., de Almeida, L. F. R., dos Santos Tozin, L. R., Marques, M. O. M., and Boaro, C. S. F. (2016). PEG-induced osmotic stress in Mentha $x$ piperita L.: structural features and metabolic responses. Plant Physiol. Biochem. 105, 174-184. doi: 10.1016/j.plaphy.2016.04.009

Bündig, C., Jozefowicz, A. M., Mock, H. P., and Winkelmann, T. (2016). Proteomic analysis of two divergently responding potato genotypes (Solanum tuberosum L.) following osmotic stress treatment in vitro. J. Proteomics 143, 227-241. doi: 10.1016/j.jprot.2016.04.048

Cakmak, I., and Horst, W. J. (1991). Effect of aluminium on lipid peroxidation, superoxide dismutase, catalase, and peroxidase activities in root tips of soybean (Glycine max). Physiol. Plant. 83, 463-468. doi: 10.1111/j.1399-3054.1991. tb00121.x

Chaitanya, K. K., and Naithani, S. C. (1994). Role of superoxide, lipid peroxidation and superoxide dismutase in membrane perturbation during loss of viability in seeds of Shorea robusta Gaertn. f. New Phytol. 126, 623-627. doi: 10.1111/j. 1469-8137.1994.tb02957.x

Chen, H., Gao, H., Fang, X., Ye, L., Zhou, Y., and Yang, H. (2015). Effects of allyl isothiocyanate treatment on postharvest quality and the activities of antioxidant enzymes of mulberry fruit. Postharvest Biol. Technol. 108, 61-67. doi: 10.1016/j. postharvbio.2015.05.011

Chen, Y., Wang, M., Hu, L., Liao, W., Dawuda, M. M., and Li, C. (2017). Carbon monoxide is involved in hydrogen gas-induced adventitious root development

\section{ACKNOWLEDGMENTS}

We thank the reviewers for their valuable comments. This work was supported by the National Natural Science Foundation of China (Nos. 31160398 and 31560563), the Post Doctoral Foundation of China (Nos. 20100470887 and 2012T50828), the Key Project of Chinese Ministry of Education (No. 211182), the Research Fund for the Doctoral Program of Higher Education (No. 20116202120005), the Natural Science Foundation of Gansu References Province, China (Nos. 1308RJZA179, 1308RJZA262, 1606RJZA073, and1606RJZA077), and Feitian and Fuxi Excellent Talents in Gansu Agricultural University in Lanzhou, China.

\section{SUPPLEMENTARY MATERIAL}

The Supplementary Material for this article can be found online at: http://journal.frontiersin.org/article/10.3389/fpls.2017.01684/ full\#supplementary-material

in cucumber under simulated drought stress. Front. Plant Sci. 8:128. doi: $10.3389 /$ fpls.2017.00128

Chen, Y. H., and Kao, C. H. (2012). Calcium is involved in nitric oxideand auxin-induced lateral root formation in rice. Protoplasma 249, 187-195. doi: 10.1007/s00709-011-0277-2

Cho, U. H., and Seo, N. H. (2005). Oxidative stress in Arabidopsis thaliana exposed to cadmium is due to hydrogen peroxide accumulation. Plant Sci. 168, 113-120. doi: 10.1016/j.plantsci.2004.07.021

Dhindsa, R. S., Plumb-Dhindsa, P., and Thorpe, T. A. (1981). Leaf senescence: correlated with increased levels of membrane permeability and lipid peroxidation, and decreased levels of superoxide dismutase and catalase. J. Exp. Bot. 32, 93-101. doi: 10.1093/jxb/32.1.93

El-Shabrawi, H., Kumar, B., Kaul, T., Reddy, M. K., Singla-Pareek, S. L., and Sopory, S. K. (2010). Redox homeostasis, antioxidant defense, and methylglyoxal detoxification as markers for salt tolerance in Pokkali rice. Protoplasma 245, 85-96. doi: 10.1007/s00709-010-0144-6

Garcia-Mata, C., and Lamattina, L. (2001). Nitric oxide induces stomatal closure and enhances the adaptive plant responses against drought stress. Plant Physiol. 126, 1196-1204. doi: 10.1104/pp.126.3.1196

Genty, B., Briantais, J. M., and Baker, N. R. (1989). The relationship between the quantum yield of photosynthetic electron transport and quenching of chlorophyll fluorescence. Biochim. Biophys. Acta 990, 87-92. doi: 10.1016/ S0304-4165(89)80016-9

González, A., de los Ángeles Cabrera, M., Henríquez, M. J., Contreras, R. A., Morales, B., and Moenne, A. (2012). Cross talk among calcium, hydrogen peroxide, and nitric oxide and activation of gene expression involving calmodulins and calcium-dependent protein kinases in Ulva compressa exposed to copper excess. Plant Physiol. 158, 1451-1462. doi: 10.1104/pp.111.191759

Górnik, K., Grzesik, M., and Romanowska-Duda, B. (2008). The effect of chitosan on rooting of grapevine cuttings and on subsequent plant growth under drought and temperature stress. J. Fruit Ornam. Plant Res. 16, 333-343.

Graziano, M., and Lamattina, L. (2007). Nitric oxide accumulation is required for molecular and physiological responses to iron deficiency in tomato roots. Plant J. 52, 949-960. doi: 10.1111/j.1365-313X.2007.03283.x

Hou, W., Sun, A. H., Chen, H. L., Yang, F. S., Pan, J. L., and Guan, M. Y. (2016). Effects of chilling and high temperatures on photosynthesis and chlorophyll fluorescence in leaves of watermelon seedlings. Biol. Plant. 60, 148-154. doi: 10.1007/s10535-015-0575-1

Humphries, E. C., and Thorne, G. N. (1964). The effect of root formation on photosynthesis of detached leaves. Ann. Bot. 28, 391-400. doi: 10.1111/j.14388677.2008.00104.x

Jaleel, C. A., Gopi, R., Sankar, B., Manivannan, P., Kishorekumar, A., Sridharan, R., et al. (2007). Studies on germination, seedling vigour, lipid peroxidation and 
proline metabolism in Catharanthus roseus seedlings under salt stress. S. Afr. J. Bot. 73, 190-195. doi: 10.1016/j.sajb.2006.11.001

Jday, A., Rejeb, K. B., Slama, I., Saadallah, K., Bordenave, M., Planchais, S., et al. (2016). Effects of exogenous nitric oxide on growth, proline accumulation and antioxidant capacity in cakile maritima seedlings subjected to water deficit stress. Funct. Plant Biol. 43, 939-948. doi: 10.1071/FP15363

Jiang, M., Yang, W., Xu, J., and Chen, Q. (1993). Active oxygen damage effect of chlorophyll degradation in rice seedlings under osmotic stress. Acta Bot. Sin. $36,289-295$

Kaur, G., Singh, H. P., Batish, D. R., Mahajan, P., Kohli, R. K., and Rishi, V. (2015). Exogenous nitric oxide (NO) interferes with lead $(\mathrm{Pb})$-induced toxicity by detoxifying reactive oxygen species in hydroponically grown wheat (Triticum aestivum) roots. PLOS ONE 10:e0138713. doi: 10.1371/journal.pone. 0138713

Kong, D. D., Ju, C. L., Parihar, A., Kim, S., Cho, D., and Kwak, J. M. (2015). Arabidopsis glutamate receptor homolog3.5 modulates cytosolic Ca2+ level to counteract effect of abscisic acid in seed germination. Plant Physiol. 167, 1630-1642. doi: 10.1104/pp.114.251298

Lang, T., Sun, H. M., Li, N. Y., Lu, Y. J., Shen, Z. D., Jing, X. S., et al. (2014). Multiple signaling networks of extracellular ATP, hydrogen peroxide, calcium, and nitric oxide in the mediation of root ion fluxes in secretor and non-secretor mangroves under salt stress. Aquat. Bot. 119, 33-43. doi: 10.1016/j.aquabot. 2014.06.009

Lanteri, M. L., Laxalt, A. M., and Lamattina, L. (2008). Nitric oxide triggers phosphatidic acid accumulation via phospholipase D during auxin-induced adventitious root formation in cucumber. Plant Physiol. 147, 188-198. doi: 10.1104/pp.107.111815

Lanteri, M. L., Pagnussat, G. C., and Lamattina, L. (2006). Calcium and calcium-dependent protein kinases are involved in nitric oxide-and auxininduced adventitious root formation in cucumber. J. Exp. Bot. 57, 1341-1351. doi: $10.1093 / j x b / e r j 109$

Larkindale, J., and Knight, M. R. (2002). Protection against heat stress-induced oxidative damage in Arabidopsis involves calcium, abscisic acid, ethylene, and salicylic acid. Plant Physiol. 128, 682-695. doi: 10.1104/pp.010320

Laspina, N. V., Groppa, M. D., Tomaro, M. L., and Benavides, M. P. (2005). Nitric oxide protects sunflower leaves against $\mathrm{Cd}$-induced oxidative stress. Plant Sci 169, 323-330. doi: 10.1016/j.plantsci.2005.02.007

Li, P., Zhao, C. Z., Zhang, Y. Q., Wang, X. M., Wang, X. Y., Wang, J. F., et al. (2016). Calcium alleviates cadmium-induced inhibition on root growth by maintaining auxin homeostasis in Arabidopsis seedlings. Protoplasma 253, 185-200. doi: 10.1007/s00709-015-0810-9

Liao, W. B., Huang, G. B., Yu, J. H., and Zhang, M. L. (2012a). Nitric oxide and hydrogen peroxide alleviate drought stress in marigold explants and promote its adventitious root development. Plant Physiol. Biochem. 58, 6-15. doi: 10.1016/ j.plaphy.2012.06.012

Liao, W. B., Huang, G. B., Yu, J. H., Zhang, M. L., and Shi, X. L. (2011). Nitric oxide and hydrogen peroxide are involved in indole-3-butyric acidinduced adventitious root development in marigold. J. Hortic. Sci. Biotechnol. 86, 159-165. doi: 10.1080/14620316.2011.11512742

Liao, W. B., Zhang, M. L., Huang, G. B., and Yu, J. H. (2012b). Ca2+ and CaM are involved in NO- and $\mathrm{H} 2 \mathrm{O} 2$-induced adventitious root development in marigold. J. Plant Growth Regul. 31, 253-264. doi: 10.1007/s00344-011-9235-7

Liao, W. B., Zhang, M. L., and Yu, J. H. (2013). Role of nitric oxide in delaying senescence of cut rose flowers and its interaction with ethylene. Sci. Hortic. 155, 30-38. doi: 10.1016/j.scienta.2013.03.005

Liu, J., Macarisin, D., Wisniewski, M., Sui, Y., Droby, S., Norelli, J., et al. (2013). Production of hydrogen peroxide and expression of ROS-generating genes in peach flower petals in response to host and non-host fungal pathogens. Plant Pathol. 62, 820-828. doi: 10.1111/j.1365-3059.2012.02683.x

Liu, W., Li, R. J., Han, T. T., Cai, W., Fu, Z. W., and Lu, Y. T. (2015). Salt stress reduces root meristem size by nitric oxide-mediated modulation of auxin accumulation and signaling in Arabidopsis. Plant Physiol. 168, 343-356. doi: 10.1104/pp.15.00030

Liu, Z., Chen, W., and He, X. (2015). Influence of Cd2+ on growth and chlorophyll fluorescence in a hyperaccumulator: Lonicera japonica Thunb. J. Plant Growth Regul. 34, 672-676. doi: 10.1007/s00344-015-9483-z

Ma, W., Smigel, A., Tsai, Y. C., Braam, J., and Berkowitz, G. A. (2008). Innate immunity signaling: cytosolic $\mathrm{Ca} 2+$ elevation is linked to downstream nitric oxide generation through the action of calmodulin or a calmodulin-like protein Plant Physiol. 148, 818-828. doi: 10.1104/pp.108.125104

Nakano, Y., and Asada, K. (1981). Hydrogen peroxide is scavenged by ascorbatespecific peroxidase in spinach chloroplasts. Plant Cell Physiol. 22, 867-880.

Neill, S. J., Desikan, R., Clarke, A., and Hancock, J. T. (2002). Nitric oxide is a novel component of abscisic acid signaling in stomatal guard cells. Plant Physiol. 128, 13-16. doi: 10.1104/pp.010707

Pagnussat, G. C., Simontacchi, M., Puntarulo, S., and Lamattina, L. (2002). Nitric oxide is required for root organogenesis. Plant Physiol. 129, 954-956. doi: 10.1104/pp.004036

Panyuta, O., Belava, V., Fomaidi, S., Kalinichenko, O., Volkogon, M., and Taran, N. (2016). The effect of pre-sowing seed treatment with metal nanoparticles on the formation of the defensive reaction of wheat seedlings infected with the eyespot causal agent. Nanoscale Res. Lett. 11, 92. doi: 10.1186/s11671-016-1305-0

Reiss, H. D., and Herth, W. (1985). Nifedipine-sensitive calcium channels are involved in polar growth of lily pollen tubes. J. Cell Sci. 76, 247-254.

Rockel, P., Strube, F., Rockel, A., Wildt, J., and Kaiser, W. M. (2002). Regulation of nitric oxide (NO) production by plant nitrate reductase in vivo and in vitro. J. Exp. Bot. 53, 103-110. doi: 10.1093/jxb/53.366.103

Romero-Puertas, M. C., Rodríguez-Serrano, M., Corpas, F. J., Gomez, M. D., and Del Rio, L. A. (2004). Cadmium-induced subcellular accumulation of O2- and $\mathrm{H} 2 \mathrm{O} 2$ in pea leaves. Plant Cell Environ. 27, 1122-1134. doi: 10.1111/j.13653040.2004.01217.x

Sadiqov, S. T., Akbulut, M., and Ehmedov, V. (2002). Role of Ca2+ in drought stress signaling in wheat seedlings. Biochemistry (Moscow) 67, 491-497. doi: 10.1023/A:1015298309888

Salgado, I., Martínez, M. C., Oliveira, H. C., and Frungillo, L. (2013). Nitric oxide signaling and homeostasis in plants: a focus on nitrate reductase and S-nitrosoglutathione reductase in stress-related responses. Braz. J. Bot. 36, 89-98. doi: 10.1007/s40415-013-0013-6

Shan, C. J., Zhou, Y., and Liu, M. J. (2015). Nitric oxide participates in the regulation of the ascorbate-glutathione cycle by exogenous jasmonic acid in the leaves of wheat seedlings under drought stress. Protoplasma 252, 1397-1405. doi: 10.1007/s00709-015-0756-y

Shi, C., Qi, C., Ren, H., Huang, A., Hei, S., and She, X. (2015). Ethylene mediates brassinosteroid -induced stomatal closure via $\mathrm{G} \alpha$ protein-activated hydrogen peroxide and nitric oxide production in Arabidopsis. Plant J. 82, 280-301. doi: $10.1111 /$ tpj. 12815

Shi, K., Li, X., Zhang, H., Zhang, G. Q., Liu, Y. R., Zhou, Y. H., et al. (2015). Guard cell hydrogen peroxide and nitric oxide mediate elevated CO2-induced stomatal movement in tomato. New Phytol. 208, 342-353. doi: 10.1111/nph.13621

Silveira, N. M., Frungillo, L., Marcos, F. C., Pelegrino, M. T., Miranda, M. T., Seabra, A. B., et al. (2016). Exogenous nitric oxide improves sugarcane growth and photosynthesis under water deficit. Planta 244, 181-190. doi: 10.1007/ s00425-016-2501-y

Silveira, N. M., Hancock, J. T., Frungillo, L., Siasou, E., Marcos, F. C., Salgado, I., et al. (2017a). Evidence towards the involvement of nitric oxide in drought tolerance of sugarcane. Plant Physiol. Biochem. 115, 354-359. doi: 10.1016/j. plaphy.2017.04.011

Silveira, N. M., Marcos, F. C., Frungillo, L., Moura, B. B., Seabra, A. B., Salgado, I., et al. (2017b). S-nitrosoglutathione spraying improves stomatal conductance, Rubisco activity and antioxidant defense in both leaves and roots of sugarcane plants under water deficit. Physiol. Plant. 160, 383-395. doi: 10.1111/ppl. 12575

Skiba, U., Smith, K. A., and Fowler, D. (1993). Nitrification and denitrification as sources of nitric oxide and nitrous oxide in a sandy loam soil. Soil Biol. Biochem. 25, 1527-1536. doi: 10.1016/0038-0717(93)90007-X

Tang, R. J., Zhao, F. G., Garcia, V. J., Kleist, T. J., Yang, L., Zhang, H. X., et al. (2015). Tonoplast CBL-CIPK calcium signaling network regulates magnesium homeostasisin Arabidopsis. Proc. Natl. Acad. Sci. U.S.A. 112, 3134-3139. doi: $10.1073 /$ pnas. 1420944112

Tian, Q. Y., Sun, D. H., Zhao, M. G., and Zhang, W. H. (2007). Inhibition of nitric oxide synthase (NOS) underlies aluminum-induced inhibition of root elongation in Hibiscus moscheutos. New Phytol. 174, 322-331. doi: 10.1111/j. 1469-8137.2007.02005.x

Tiwari, A., Singh, P., and Asthana, R. K. (2016). Role of calcium in the mitigation of heat stress in the cyanobacterium Anabaena PCC 7120. J. Plant Physiol. 199, 67-75. doi: 10.1016/j.jplph.2016.05.012 
Uchida, A., Jagendorf, A. T., Hibino, T., Takabe, T., and Takabe, T. (2002). Effects of hydrogen peroxide and nitric oxide on both salt and heat stress tolerance in rice. Plant Sci. 163, 515-523. doi: 10.1016/S0168-9452(02)00159-0

Velikova, V., Yordanov, I., and Edreva, A. (2000). Oxidative stress and some antioxidant systems in acid rain-treated bean plants: protective role of exogenous polyamines. Plant Sci. 151, 59-66. doi: 10.1016/S0168-9452(99) 00197-1

Wang, P., Zhu, J. K., and Lang, Z. (2015). Nitric oxide suppresses the inhibitory effect of abscisic acid on seed germination by S-nitrosylation of SnRK2 proteins. Plant Signal. Behav. 10:e1031939. doi: 10.1080/15592324.2015.1031939

Wang, W. H., Yi, X. Q., Han, A. D., Liu, T. W., Chen, J., Wu, F. H., et al. (2012). Calcium-sensing receptor regulates stomatal closure through hydrogen peroxide and nitric oxide in response to extracellular calcium in Arabidopsis. J. Exp. Bot. 63, 177-190. doi: 10.1093/jxb/err259

Wang, Y. H., Chen, T., Zhang, C. Y., Hao, H. Q., Liu, P., Zheng, M. Z., et al. (2009). Nitric oxide modulates the influx of extracellular $\mathrm{Ca} 2+$ and actin filament organization during cell wall construction in Pinus bungeana pollen tubes. New Phytol. 182, 851-862. doi: 10.1111/j.1469-8137.2009.02820.x

Wang, Y. S., and Yang, Z. M. (2005). Nitric oxide reduces aluminum toxicity by preventing oxidative stress in the roots of Cassia tora L. Plant Cell Physiol. 46, 1915-1923. doi: 10.1093/pcp/pci202

Wilson, M. E., Basu, M. R., Bhaskara, G. B., Verslues, P. E., and Haswell, E. S. (2014). Plastid osmotic stress activates cellular stress responses in Arabidopsis. Plant Physiol. 165, 119-128. doi: 10.1104/pp.114.236620

Wu, G. Q., Feng, R. J., and Shui, Q. Z. (2016). Effect of osmotic stress on growth and osmolytes accumulation in sugar beet (Beta vulgaris L.) plants. Plant Soil Environ. 62, 189-194. doi: 10.17221/101/2016-PSE

$\mathrm{Xu}, \mathrm{C}$., Li, X., and Zhang, L. (2013). The effect of calcium chloride on growth, photosynthesis, and antioxidant responses of Zoysia japonica under drought conditions. PLOS ONE 8:e68214. doi: 10.1371/journal.pone.0068214

Xu, Y. F., Chu, X. T., Fu, J. J., Yang, L. Y., and Hu, T. M. (2016). Crosstalk of nitric oxide with calcium induced tolerance of tall fescue leaves to high irradiance. Biol. Plant 60, 376-384. doi: 10.1007/s10535-016-0597-3

Xuan, W., Zhu, F. Y., Xu, S., Huang, B. K., Ling, T. F., Qi, J. Y., et al. (2008). The heme oxygenase/carbon monoxide system is involved in the auxininduced cucumber adventitious rooting process. Plant Physiol. 148, 881-893. doi: 10.1104/pp.108.125567

Yang, W., Zhu, C., Ma, X., Li, G., Gan, L., Ng, D., et al. (2013). Hydrogen peroxide is a second messenger in the salicylic acid-triggered adventitious rooting process in mung bean seedlings. PLOS ONE 8:e84580. doi: 10.1371/ journal.pone.0084580

Zhang, W. H., Rengel, Z., and Kuo, J. (1998). Determination of intracellular $\mathrm{Ca} 2+$ in cells of intact wheat roots: loading of acetoxymethyl ester of Fluo-3 under low temperature. Plant J. 15, 147-151. doi: 10.1046/j.1365-313X.1998. 00188.x

Zhang, X. W., Dong, Y. J., Qiu, X. K., Hu, G. Q., Wang, Y. H., and Wang, Q. H. (2012). Exogenous nitric oxide alleviates iron-deficiency chlorosis in peanut growing on calcareous soil. Plant Soil Environ. 58, 111-120.

Zhao, H. J., and Tan, J. F. (2005). Role of calcium ion in protection against heat and high irradiance stress-induced oxidative damage to photosynthesis of wheat leaves. Photosynthetica 43, 473-476. doi: 10.1007/s11099-005-0076-0

Zhao, X., Wang, J., Yuan, J., Wang, X. L., Zhao, Q. P., Kong, P. T., et al. (2015). Nitric Oxide-Associated Protein1 (AtNOA1) is essential for salicylic acid-induced root waving in Arabidopsis thaliana. New Phytol. 207, 211-224. doi: $10.1111 /$ nph. 13327

Zhou, L. M., Lan, W. Z., Jiang, Y. Q., Fang, W., and Luan, S. (2014). A calciumdependent protein kinase interacts with and activates a calcium channel to regulate pollen tube growth. Mol. Plant 7, 369-376. doi: 10.1093/mp/sst125

Zhu, Y. C., Liao, W. B., Niu, L. J., Wang, M., and Ma, Z. J. (2016). Nitric oxide is involved in hydrogen gas-induced cell cycle activation during adventitious root formation in cucumber. BMC Plant Biol. 16:146. doi: 10.1186/s12870-0160834-0

Zorrilla-Fontanesi, Y., Rouard, M., Cenci, A., Kissel, E., Do, H., Dubois, E., et al. (2016). Differential root transcriptomics in a polyploid non-model crop: the importance of respiration during osmotic stress. Sci. Rep. 6:22583. doi: 10.1038/ srep22583

Zou, J. J., Li, X. D., Ratnasekera, D., Wang, C., Liu, W. X., Song, L. F., et al. (2015). Arabidopsis Calcium-Dependent Protein Kinse8 and Catalase 3 function in abscisic acid-mediated signaling and $\mathrm{H} 2 \mathrm{O} 2$ homeostasis in stomatal guard cells under drought stress. Plant Cell 27, 1445-1460. doi: 10.1105/tpc.15. 00144

Zou, J. J., Wei, F. J., Wang, C., Wu, J. J., Ratnasekera, D., Liu, W. X., et al. (2010). Arabidopsis calcium-dependent protein kinase CPK10 functions in abscisic acid-and $\mathrm{Ca} 2+-$ mediated stomatal regulation in response to drought stress. Plant Physiol. 154, 1232-1243. doi: 10.1104/pp.110.157545

Conflict of Interest Statement: The authors declare that the research was conducted in the absence of any commercial or financial relationships that could be construed as a potential conflict of interest.

Copyright (C) $2017 \mathrm{Niu}, \mathrm{Yu}$, Liao, Yu, Zhang and Dawuda. This is an open-access article distributed under the terms of the Creative Commons Attribution License (CC BY). The use, distribution or reproduction in other forums is permitted, provided the original author(s) or licensor are credited and that the original publication in this journal is cited, in accordance with accepted academic practice. No use, distribution or reproduction is permitted which does not comply with these terms. 